Supporting Information for:

\title{
Synthesis and Characterization of a Stable High- Valent Cobalt Carbene Complex
}

James A. Bellow, Sebastian A. Stoian, Johan van Tol, Andrew Ozarowski, Richard L. Lord,* Stanislav Groysman*

Table of Contents Page

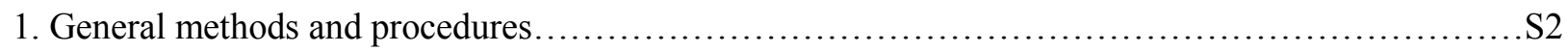

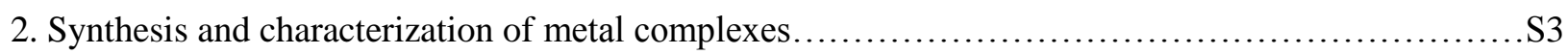

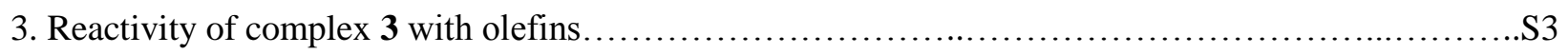

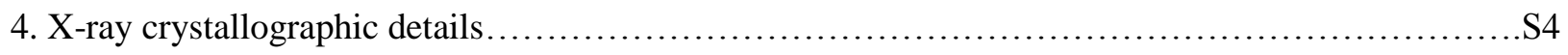

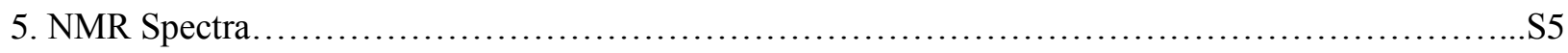

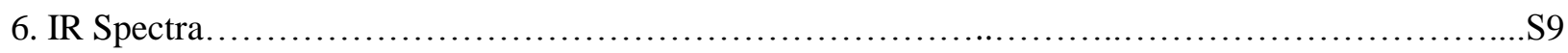

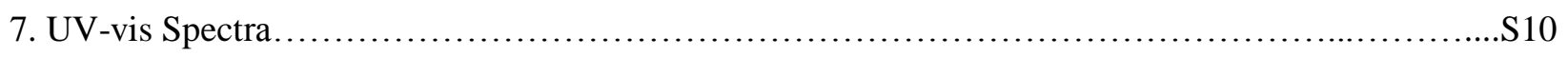

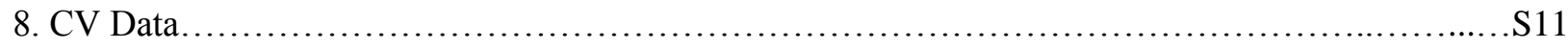

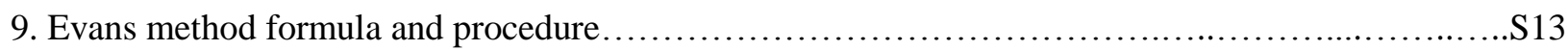

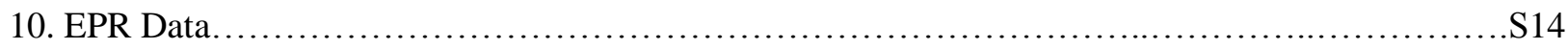

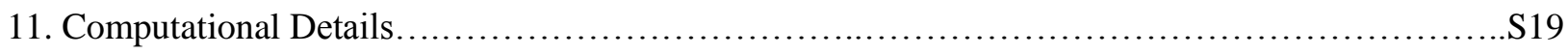

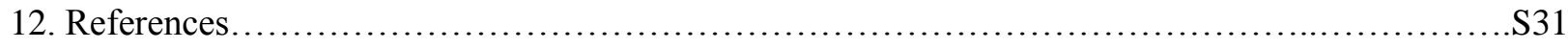




\section{General methods and procedures}

All reactions involving air-sensitive materials were executed in a nitrogen-filled glovebox. The syntheses of the iron and cobalt bis(alkoxide) complexes $\mathbf{1}$ and $\mathbf{2}$ were reported previously. ${ }^{1,2}$

Diphenyldiazomethane was synthesized according to a reported literature procedure. ${ }^{3}$ All solvents were purchased from Fisher Scientific and were of HPLC grade. The solvents were purified using an MBRAUN solvent purification system and stored over 3- $\AA$ molecular sieves. The complexes were characterized using NMR, IR, UV/Vis and EPR spectroscopies, X-ray crystallography, elemental analysis, and the Evans method. NMR spectra were recorded at the Lumigen Instrument Center (Wayne State University) on a Varian Mercury $400 \mathrm{MHz}$ NMR Spectrometer in $\mathrm{C}_{6} \mathrm{D}_{6}$ at room temperature. IR spectra of powdered samples were recorded on a Shimadzu IR Affinity-1 FT-IR Spectrometer outfitted with a MIRacle10 attenuated total reflectance accessory with a monolithic diamond crystal stage and pressure clamp. UV-visible spectra were obtained on a Shimadzu UV-1800 spectrometer. Elemental analyses were performed by Midwest Microlab LLC.

The continuous-wave and pulsed X-Band $(9.4 \mathrm{GHz})$ EPR spectra were recorded using a Bruker ElexSys 680 spectrometer that is part of the instrumentation available to NHMFL users. All spectra were recorded at cryogenic temperatures using a helium-flow cryostat (Oxford). While all pulsed spectra were obtained using a cylindrical $\mathrm{TE}_{011}$ dielectric ring resonator (ER 4118X-MD-5, Bruker) some of those in continuous wave mode were recorded using a high-sensitivity cavity (ER 4119HS, Bruker). The HYSCORE spectra were recorded using a standard four-pulse sequence $\pi / 2-\tau-\pi / 2-t_{1}-\pi-t_{2}-\pi / 2-e c h o{ }^{4}$ Unwanted pulses were removed using an eight-step phase cycle. ${ }^{5}$ The length of the $\pi$ and $\pi / 2$ pulses was $16 \mathrm{~ns}$ and a delay, $\tau$, of $200 \mathrm{~ns}$ was employed. The echo was recorded as function of two dimensions, $\mathrm{t}_{1}$ and $t_{2}$, with a step size $\mathrm{dt}_{1,2}$ of $8 \mathrm{~ns}$ for 512 points per dimension. The experimentally determined timedomain data was processed to yield the frequency-domain plot presented below. Thus, the background echo decay for both $t_{1}$ and $t_{2}$ was removed by subtracting a third order polynomial fitted to the individual data traces. Subsequently, both dimensions were expanded to 1024 points by zero-filling the empty data points followed by a convolution with a Hamming widow function. The resulting data set was submitted to a two-dimensional Fourier transform yielding the frequency-domain HYSCORE spectrum. For the current manuscript only the positive, $(+,+)$, quadrant is presented. The high-frequency EPR spectra were obtained using a custom-built spectrometer available at the EMR facility of NHMFL. This spectrometer allows for recording spectra transmission mode. The microwaves are propagated through cylindrical lightpipes and were generated by a phase-locked oscillator (Virginia Diodes) operating at a frequency of $13 \pm 1 \mathrm{GHz}$ and generating its harmonics, of which the 4th, 8th, 16th, 24th and 32nd were available. A superconducting magnet (Oxford Instruments) capable of reaching a field of $17 \mathrm{~T}$ was employed. All spectral simulations were performed in the framework described by the spin-Hamiltonian of equation 1 , where $\xi=x, y, z$.

$$
\widehat{\mathrm{H}}=\beta_{e} \overrightarrow{\mathbf{B}} \cdot \tilde{\mathbf{g}} \cdot \tilde{\mathbf{S}}-\sum_{\xi}\left(\beta_{n} g_{n} \overrightarrow{\mathbf{B}} \cdot \tilde{\mathbf{I}}_{\xi}+\tilde{\mathbf{I}}_{\xi} \cdot \widetilde{\mathbf{A}}_{\xi} \cdot \tilde{\mathbf{S}}\right)
$$

The simulations of Figure 2 were obtained using the SpinCount program written by Prof. Mike Hendrich at Carnegie Mellon University, ${ }^{6}$ and relied on a first-order perturbative treatment of the hyperfine interaction. In contrast, the simulations of Figure S9 were obtained using a program written by Dr. Andrew Ozarowski and involved the diagonalization of the complex, $16 \times 16$ spin-Hamiltonian matrix. All spectra could be successfully simulated using $S=1 / 2, \mathrm{~g}_{\mathrm{x}}=3.06(2), \mathrm{g}_{\mathrm{y}}=2.24(2), \mathrm{g}_{\mathrm{z}}=1.93(2), \sigma\left(\mathrm{g}_{\mathrm{x}}\right)=$ 
$0.03(2), \sigma\left(\mathrm{g}_{\mathrm{y}}\right)=0.01(1), \sigma\left(\mathrm{g}_{\mathrm{z}}\right)=0.01(1), \mathrm{A}_{\mathrm{x}}=585 \mathrm{MHz}, \mathrm{A}_{\mathrm{y}}=280 \mathrm{MHz}, \mathrm{A}_{\mathrm{z}}=230 \mathrm{MHz}, \sigma\left(\mathrm{A}_{\mathrm{x}}\right)=25$

$\mathrm{MHz}, \sigma\left(\mathrm{A}_{\mathrm{y}}\right)=10 \mathrm{MHz}, \sigma\left(\mathrm{A}_{\mathrm{z}}\right)=5 \mathrm{MHz}$, an intrinsic Lorentzian linewidth $\Gamma=15 \mathrm{G}$. While the X-band spectra were recorded for deuterated-toluene solutions those recorded at high-frequency were obtained using non-deuterated toluene solutions. The simulations of the HYSCORE spectra presented in Figure S17 were obtained using the EasySpin software package maintained and developed by Prof. Stefan Stoll. ${ }^{7}$

\section{Synthesis and characterization of metal complexes}

Reaction of $\mathbf{1}$ with $\mathbf{P h}_{\mathbf{2}} \mathbf{C N}_{2}$. To a stirring hexane solution of $\mathbf{1}$ (27.1 mg, $0.042 \mathrm{mmol}$ ) was added dropwise a hexane solution of diphenyldiazomethane $(8.2 \mathrm{mg}, 0.042 \mathrm{mmol})$, leading to an instantaneous color change to red. The reaction was stirred for an hour, upon which the volatiles were removed in vacuo to give a red residue. This residue was dissolved in pentane, filtered, and concentrated. Crystallization at $35^{\circ} \mathrm{C}$ afforded colorless crystals confirmed by NMR to be benzophenone azine, $\mathrm{Ph}_{2} \mathrm{CNNCPh}_{2}(4.6 \mathrm{mg}$, $60 \%)$.

$\operatorname{Co}(\mathrm{OR})_{2}\left(\mathbf{C P h}_{2}\right)(3)$. To a stirring hexane solution of $\mathrm{Co}(\mathrm{OR})_{2}(\mathrm{THF})_{2}(30.1 \mathrm{mg}, 0.05 \mathrm{mmol})$ was added dropwise a hexane solution of diphenyldiazomethane $(9.1 \mathrm{mg}, 0.05 \mathrm{mmol})$. Gradually the solution color changed from violet to red. The reaction was stirred for an hour, upon which the volatiles were removed in vacuo. The resulting red-brown residue was redissolved in pentane, filtered, and concentrated. Crystallization at $-35{ }^{\circ} \mathrm{C}$ afforded the product as red-brown crystals $(26.6 \mathrm{mg}, 85 \%)$. IR $\left(\mathrm{cm}^{-1}\right): 3051(\mathrm{w})$, 3001 (w), 2963 (w), 2878 (w), 2832 (w), 1474 (w), 1439 (m), 1400 (w), 1385 (w), 1188 (w), 1153 (w), $1084(\mathrm{w}), 1042(\mathrm{~s}), 991(\mathrm{~s}), 899(\mathrm{~m}), 756(\mathrm{~s}), 702(\mathrm{~s}), 687(\mathrm{~s}), 648(\mathrm{~m}) \cdot \mu_{\mathrm{eff}}=2.0 \pm 0.1 \mu \mathrm{B} . \lambda_{\max }\left(\varepsilon_{\mathrm{M}}\right) 483$ (2041). The compound was also characterized by X-ray crystallography. Anal. Calcd. for $\mathrm{C}_{43} \mathrm{H}_{56} \mathrm{O}_{2} \mathrm{Co}$ : C, 77.8; H, 8.5. Found: C, 77.9; H, 8.6.

\section{Reactivity of complex 3 with olefins}

Stoichiometric reaction of 3 with styrene. Complex $3(15.5 \mathrm{mg}, 0.023 \mathrm{mmol})$ and styrene $(2.4 \mathrm{mg}$, $0.023 \mathrm{mmol}$ ) were combined in deuterated toluene in an NMR tube under an atmosphere of dinitrogen. The tube was sealed with parafilm and heated in an oil bath at either 60 or $90{ }^{\circ} \mathrm{C}$ for four hours. Gradually the solution color changed to green-brown. NMR indicated about $15 \%$ conversion of the styrene to the respective cyclopropane, whose peaks were similar to those reported in the literature. ${ }^{8}$ After one hour, no further increase in cyclopropane formation was observed.

Stoichiometric reaction of 3 with methyl acrylate. Complex 3 (17.9 mg, $0.027 \mathrm{mmol})$ and methyl acrylate $(2.3 \mathrm{mg}, 0.027 \mathrm{mmol})$ were combined in deuterated toluene in an NMR tube under an atmosphere of dinitrogen. The tube was sealed with parafilm and heated in an oil bath at $90{ }^{\circ} \mathrm{C}$ for four hours. Gradually the solution color changed to blue-violet. NMR indicated no formation of cyclopropane, accompanied by some decomposition of the carbene complex.

Catalytic reaction of 3 with styrene. Diphenyldiazomethane $(31.2 \mathrm{mg}, 0.16 \mathrm{mmol})$ and styrene (16.7 $\mathrm{mg}, 0.16 \mathrm{mmol}$ ) were combined in an NMR tube, along with $10 \mathrm{~mol} \%$ of complex $\mathbf{3}$ and 1,3,5trimethoxybenzene as an internal standard. Gas evolution was immediately observed. The NMR tube was sealed with parafilm and heated in an oil bath at $90{ }^{\circ} \mathrm{C}$ for four hours. About one equivalent of the respective cyclopropane was formed, but no additional cyclopropane formation was observed after one hour of continued heating. 


\section{X-ray crystallographic details}

The structure of $\mathbf{3}$ was confirmed by X-ray analysis. The crystals were mounted on a Bruker APEXII/Kappa three circle goniometer platform diffractometer equipped with an APEX-2 detector. A graphic monochromator was employed for wavelength selection of the Mo K $\alpha$ radiation $(\lambda=0.71073 \AA)$.

The data was collected at 100(2) K. The data were processed and the structure was solved using the APEX-2 software supplied by Bruker-AXS. The structure was refined by standard difference Fourier techniques with SHELXL (6.10 v., Sheldrick G. M., and Siemens Industrial Automation, 2000). Hydrogen atoms were placed in calculated positions using a standard riding model and refined isotropically; all other atoms were refined anisotropically.

Table S1. Crystal data and structure refinement for 3 .

\begin{tabular}{|c|l|}
\hline formula & $\mathrm{C}_{43} \mathrm{H}_{56} \mathrm{O}_{2} \mathrm{Co}$ \\
\hline $\mathrm{fw}$ & 663.81 \\
\hline crystal system & triclinic \\
\hline space group & $P-1$ \\
\hline$a(\AA)$ & $8.5434(4)$ \\
\hline$b(\AA)$ & $11.3181(5)$ \\
\hline$c(\AA)$ & $19.6570(10)$ \\
\hline$\alpha(\mathrm{deg})$ & $106.087(2)$ \\
\hline$\beta(\mathrm{deg})$ & $96.817(2)$ \\
\hline$\gamma(\mathrm{deg})$ & $97.583(2)$ \\
\hline$V\left(\AA^{3}\right)$ & $1786.12(15)$ \\
\hline$D_{c}\left(\mathrm{~g} \mathrm{~cm}^{-3}\right)$ & 1.234 \\
\hline$Z$ & 2 \\
\hline$\mu\left(\mathrm{mm}^{-1}\right)$ & 0.516 \\
\hline$T(\mathrm{~K})$ & $100(2)$ \\
\hline$R_{I}$ & 6.38 \\
\hline $\mathrm{GOF}$ & 1.120 \\
\hline
\end{tabular}




\section{NMR Spectra}

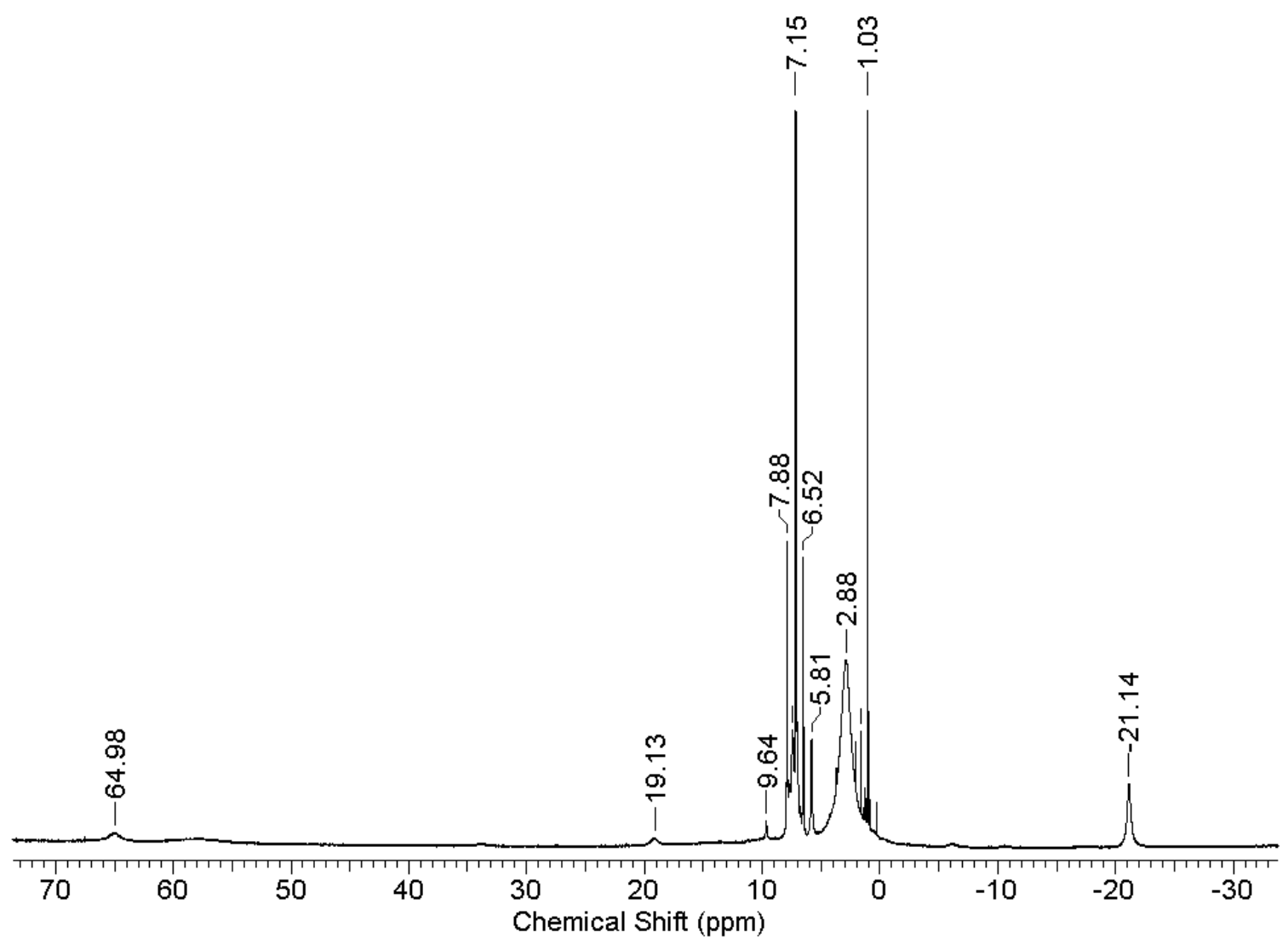

Figure S1: NMR spectrum of complex 3. 


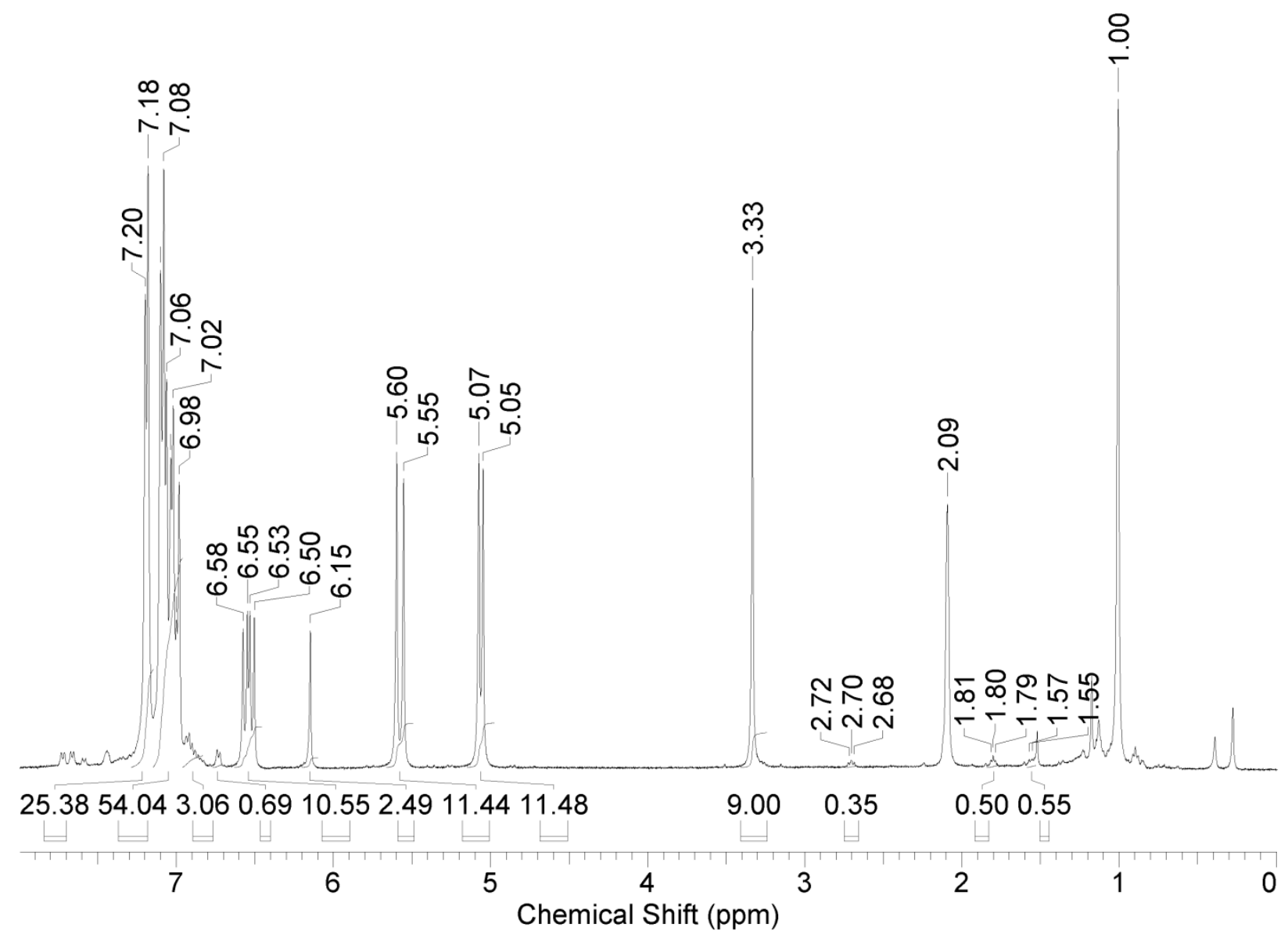

Figure S2: ${ }^{1} \mathrm{H}$ NMR spectrum of a stoichiometric reaction of $\mathbf{3}$ with styrene. Approximately $15 \%$ conversion of the olefin to the cyclopropane after four hours of heating at $90{ }^{\circ} \mathrm{C}$. 


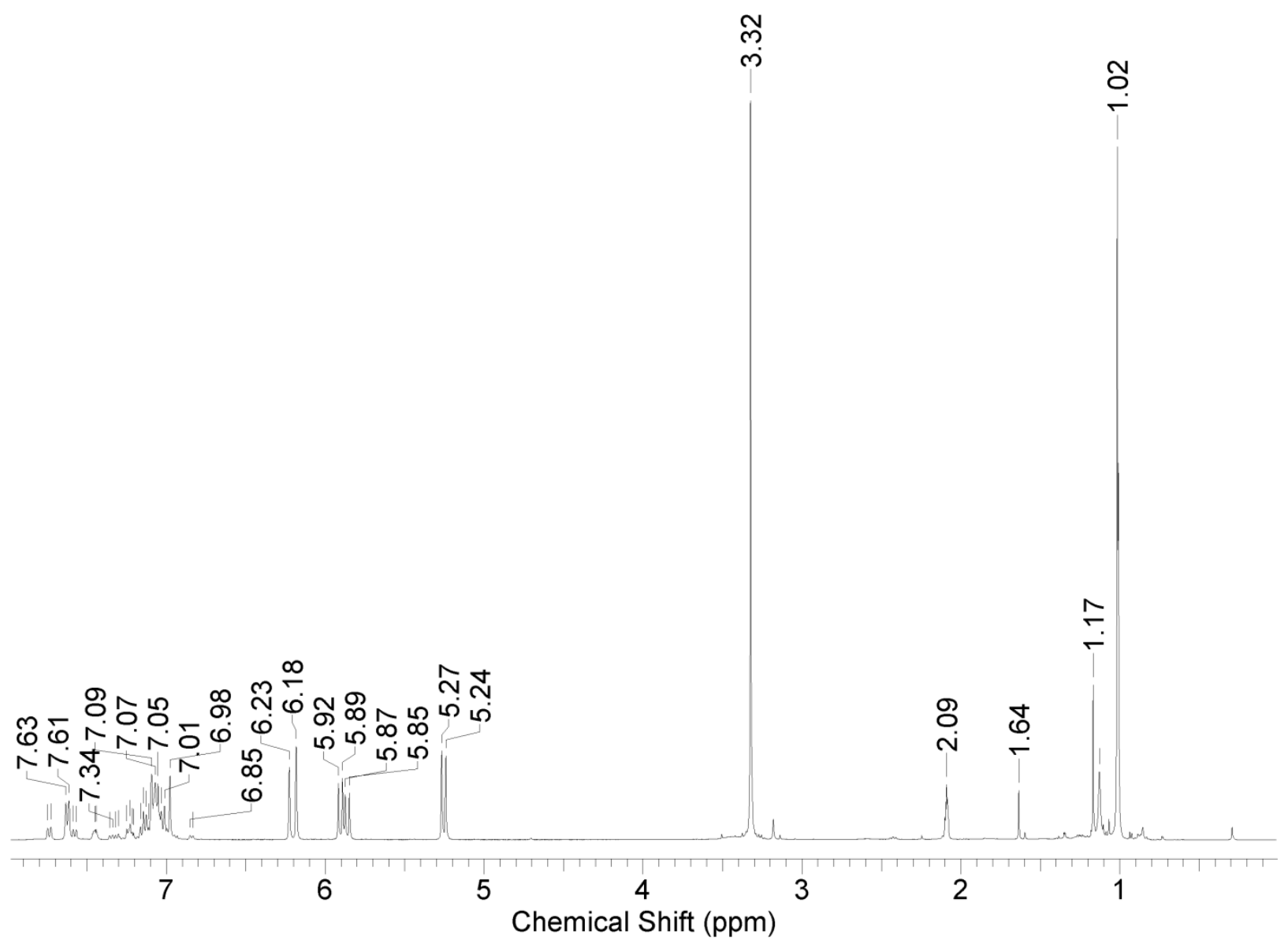

Figure S3: ${ }^{1} \mathrm{H}$ NMR spectrum of the stoichiometric reaction of $\mathbf{3}$ with methyl acrylate. The reaction was heated for four hours at $90{ }^{\circ} \mathrm{C}$. Decomposition of $\mathbf{3}$ is observed, with negligible cyclopropane formation. 


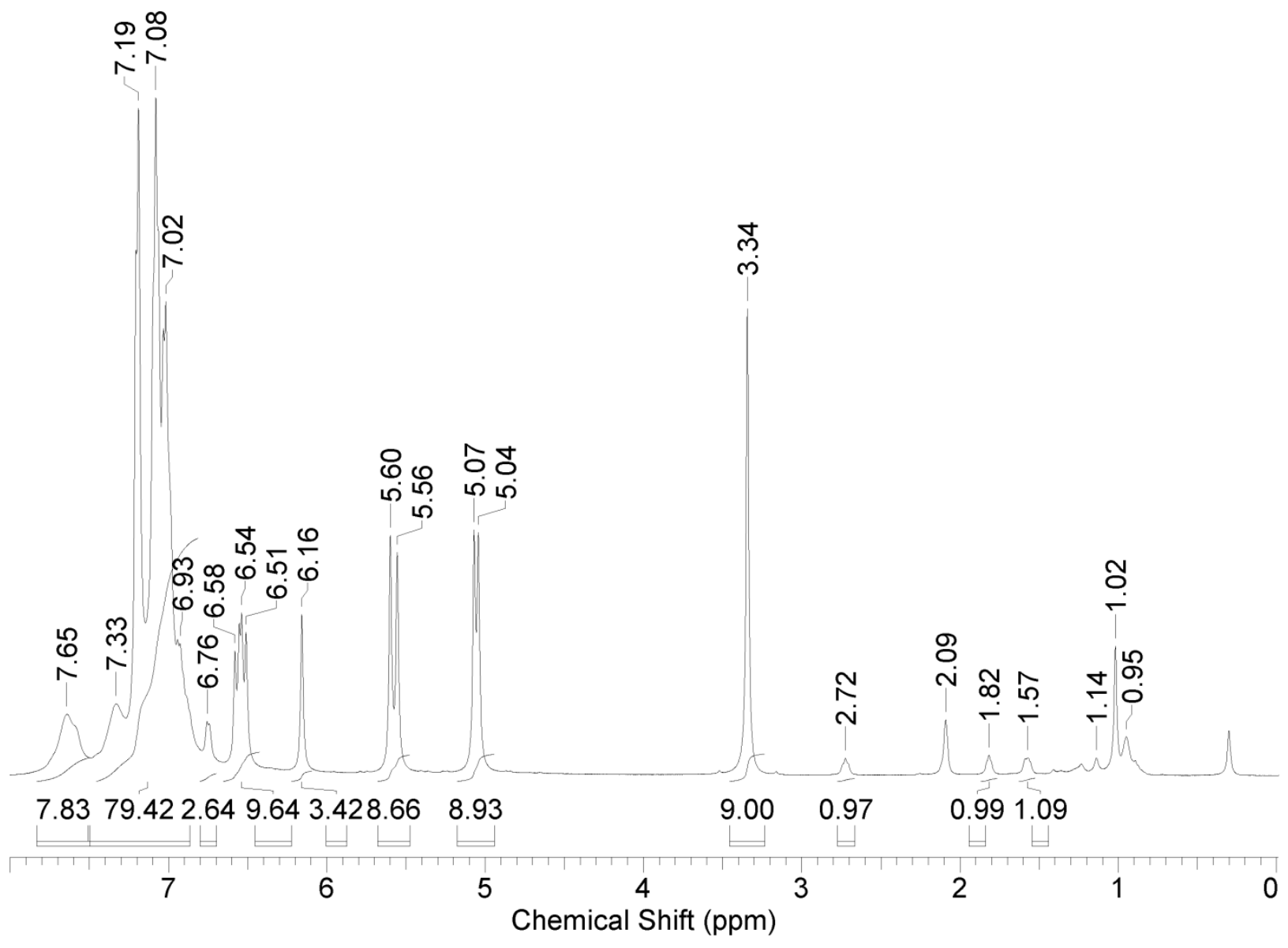

Figure S4: ${ }^{1} \mathrm{H}$ NMR spectrum of the catalytic reaction of styrene with diphenyldiazomethane using 10 mol $\%$ of 3 . Trimethoxybenzene was used as an internal standard. About one equivalent of the corresponding cyclopropane was formed after four hours of heating at $90{ }^{\circ} \mathrm{C}$. 


\section{IR Spectra}

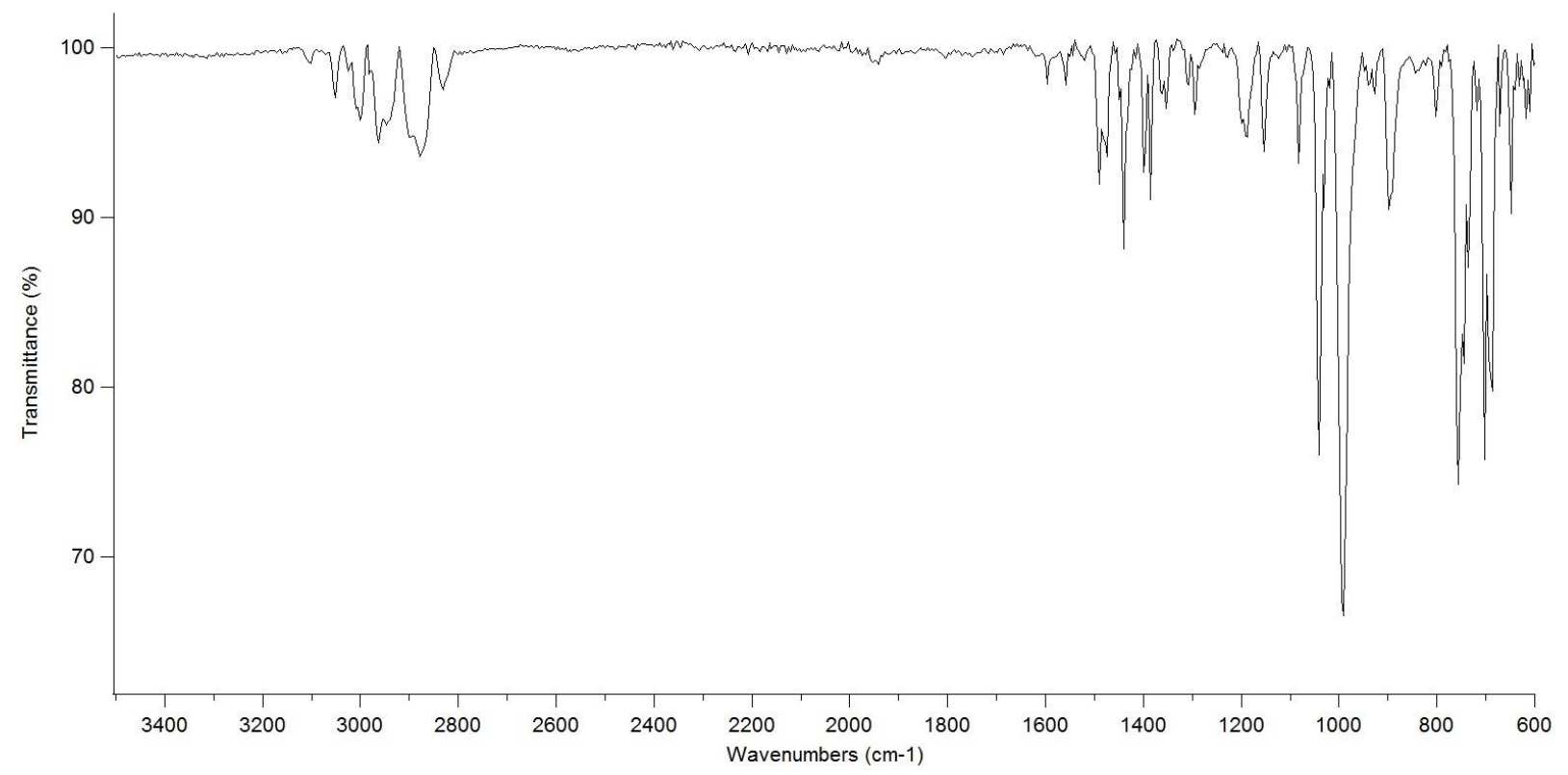

Figure S5: IR spectrum of complex 3 . 


\section{UV-vis Spectra}

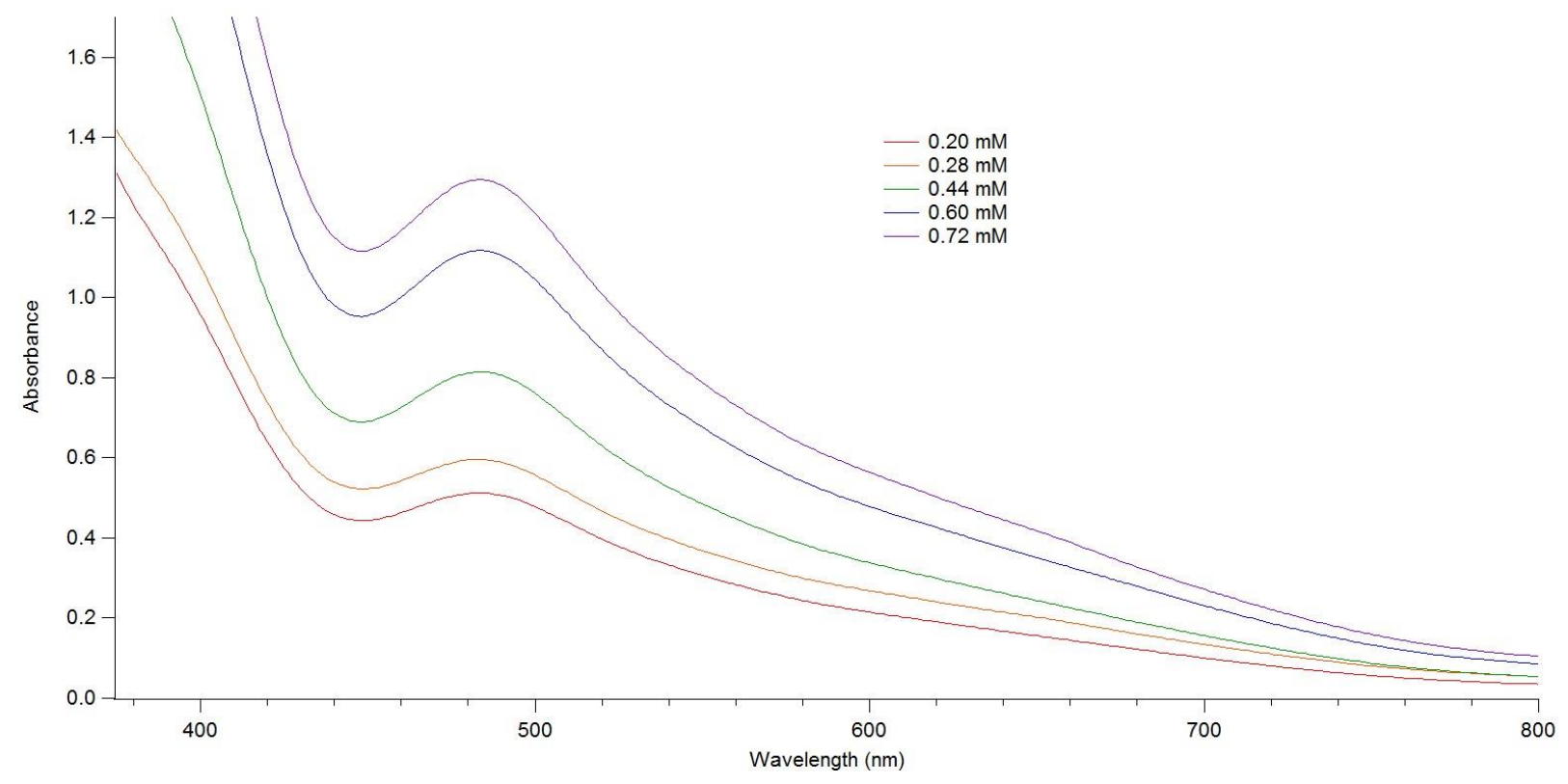

Figure S6: UV/vis spectra for complex 3 at five different concentrations. 


\section{CV Data}

Electrochemical properties were determined using cyclic voltammetry on a BAS Epsilon system in a nitrogen-filled glovebox. Samples were prepared in anhydrous THF with $0.1 \mathrm{M}$ tetrabutylammonium hexafluorophosphate $\left[\mathrm{NBu}_{4}\right]\left(\mathrm{PF}_{6}\right)$ as the supporting electrolyte. Redox potentials were determined with a scan rate of $100 \mathrm{mV} / \mathrm{s}$ at $25^{\circ} \mathrm{C}$ by using a platinum disc working electrode ( $2 \mathrm{~mm}$ diameter), a platinum wire counter electrode, and a nonaqueous $\mathrm{Ag}^{+} / \mathrm{Ag}$ reference electrode, and referenced to ferrocene/ ferrocenium couple.

Large peak separations on the order of $300 \mathrm{mV}$ or greater were observed for each redox event, suggesting quasi-reversible processes. Cyclic voltammetry measurements were also taken at various scan rates from $25-100 \mathrm{mV} / \mathrm{s}$. Small decreases in the peak separations were observed at lower scan rates, further supporting quasi-reversible processes.

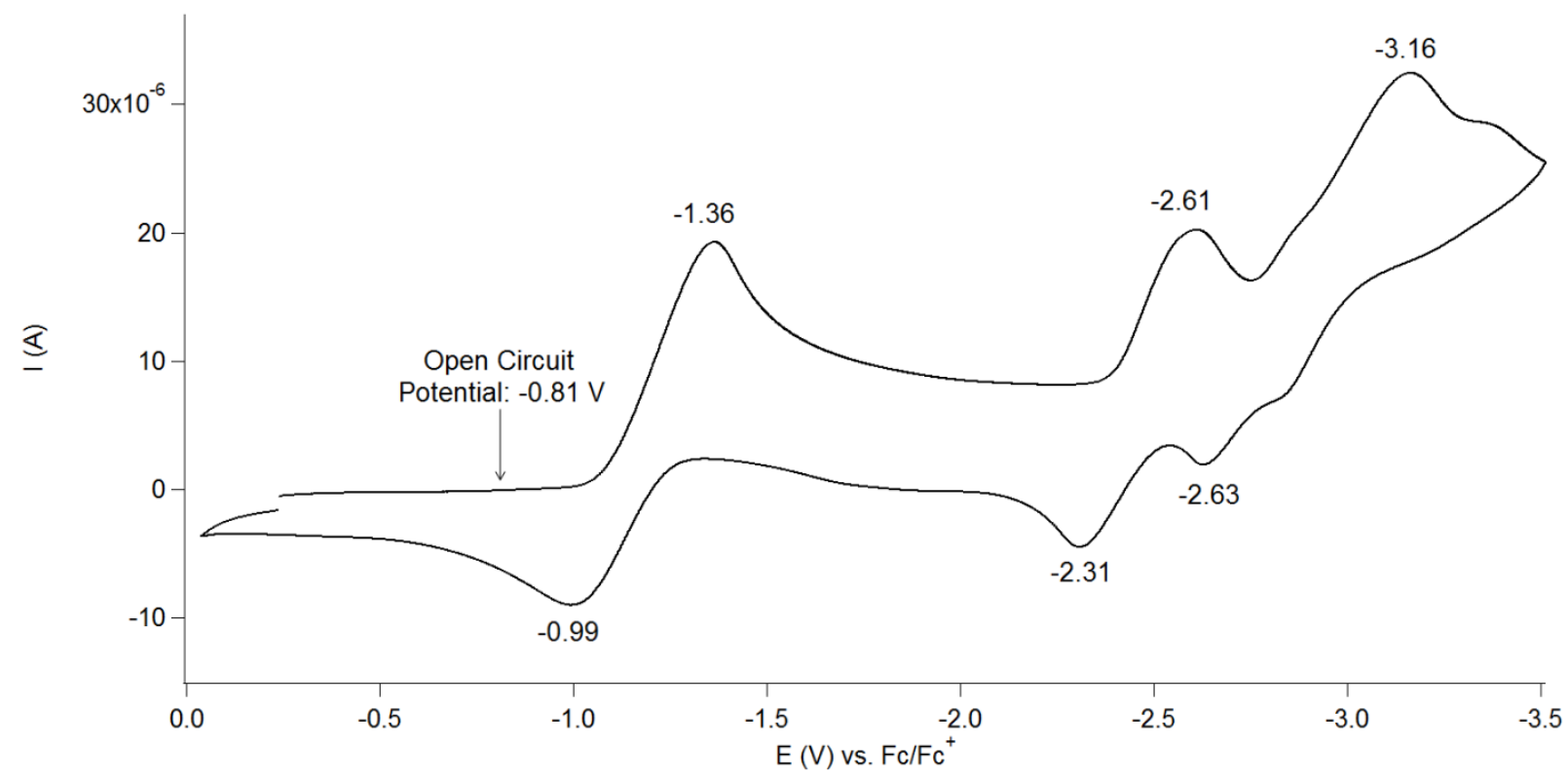

Figure S7: $\mathrm{CV}$ of compound 3 in THF $\left(0.1 \mathrm{M}\left[\mathrm{NBu}_{4}\right]\left(\mathrm{PF}_{6}\right), 25^{\circ} \mathrm{C}\right.$, platinum working electrode, 100 $\mathrm{mV} / \mathrm{s} \mathrm{scan}$ rate). 


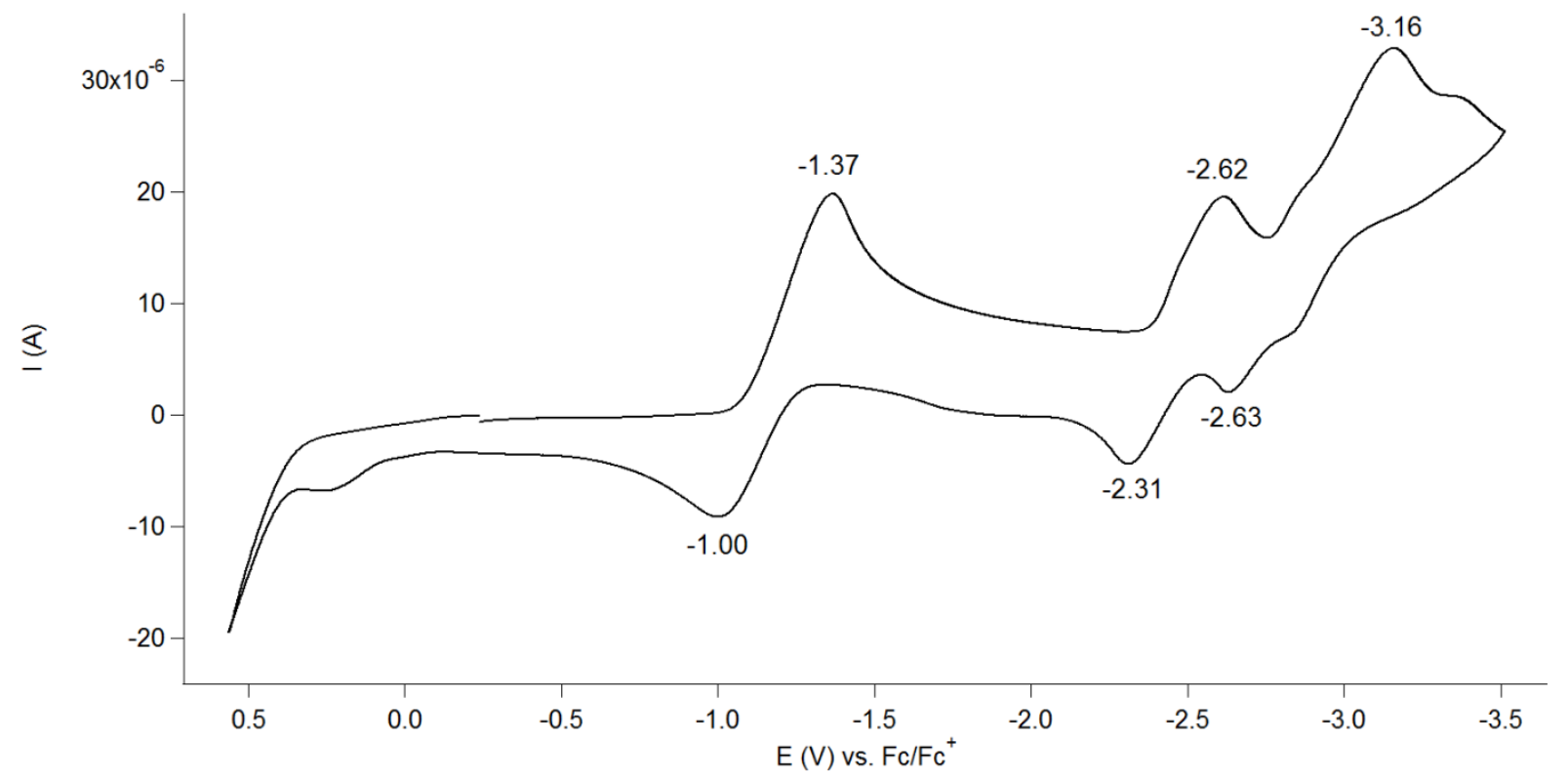

Figure S8: CV of compound 3 in THF across full working potential range $\left(0.1 \mathrm{M}\left[\mathrm{NBu}_{4}\right]\left(\mathrm{PF}_{6}\right), 25^{\circ} \mathrm{C}\right.$, platinum working electrode, $100 \mathrm{mV} / \mathrm{s}$ scan rate).

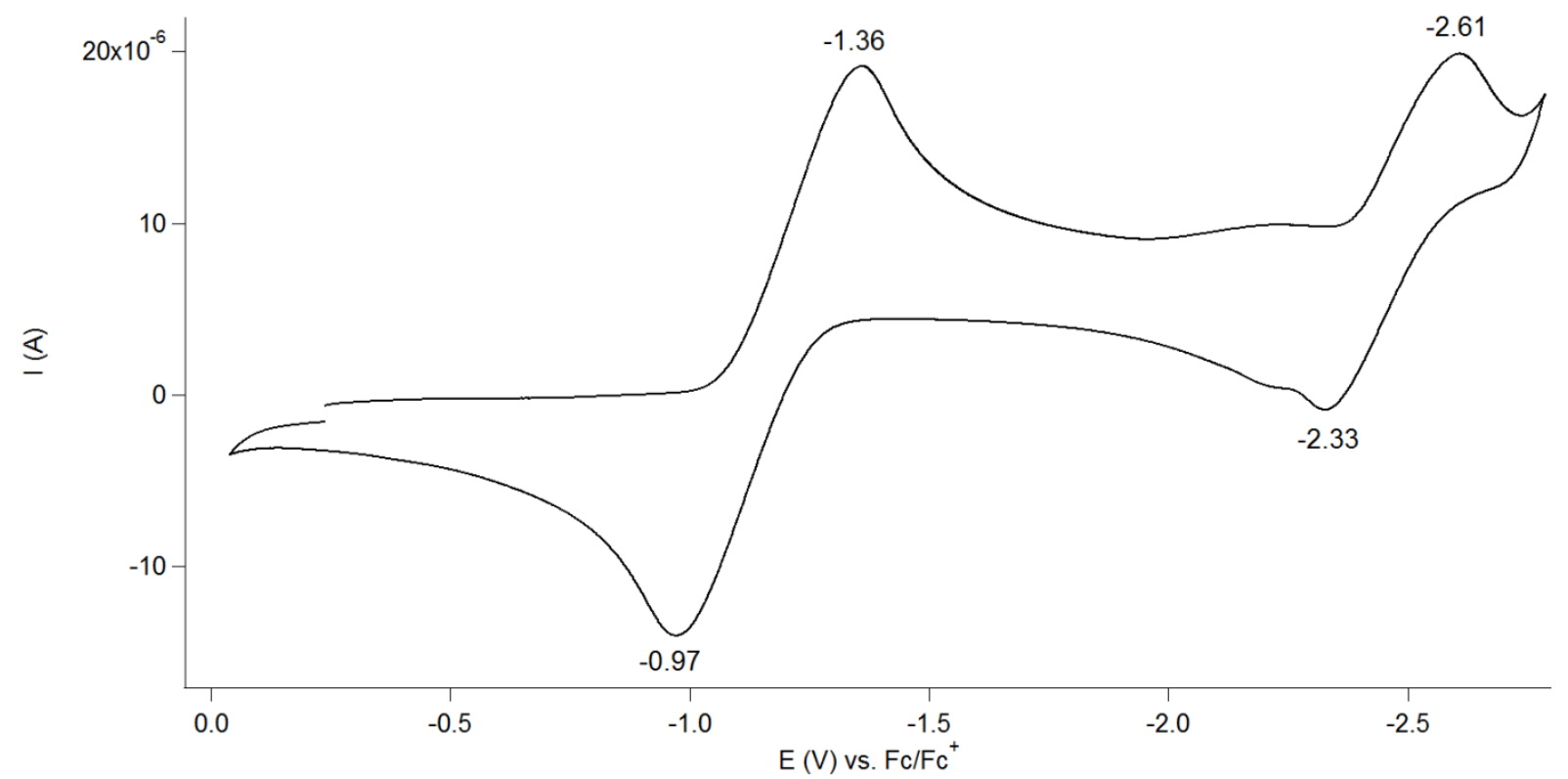

Figure S9: $\mathrm{CV}$ of compound 3 in THF, cycled after the second redox event $\left(0.1 \mathrm{M}\left[\mathrm{NBu}_{4}\right]\left(\mathrm{PF}_{6}\right), 25^{\circ} \mathrm{C}\right.$, platinum working electrode, $100 \mathrm{mV} / \mathrm{s}$ scan rate). 


\section{Evans method formula and procedure}

The Evans method was performed on complex 3 using a Wilmad coaxial insert (purchased from Aldrich) and a standard NMR tube. The sample was carefully weighed, and a precise amount of the appropriate NMR solvent was added to afford solutions with known concentrations for the calculations. The solutions were added to the insert, and the insert was placed inside the outer NMR tube, which contained blank NMR solvent. NMR spectra were taken as indicated previously. The molar susceptibility $\chi_{m}$ of the compound was first calculated using Equation $2:^{9}$

$$
\chi_{m}=\left[\frac{3 \Delta v}{4 \pi m v_{0}}+\chi_{0}\right] M
$$

where $\Delta v$ is the peak separation in Hertz, $m$ is the concentration of the solution in grams per milliliter, $v_{0}$ is the spectrometer operating frequency in Hertz, $\chi_{0}$ is the molar susceptibility of the solvent (in $\mathrm{cm}^{3} / \mathrm{g}$ ), and $M$ is the molar mass of the compound ( $\mathrm{g} / \mathrm{mol}$ ). Molar susceptibilities (Pascal's constants) of the solvents used were obtained from Journal of Chemical Education. ${ }^{9}$

The solution state effective magnetic moment $\left(\mu_{e f f}\right)$ was calculated using Equation 3:

$$
\mu_{e f f}=\sqrt{\left(2.383 \times 10^{3}\right)\left(\chi_{m}\right)}
$$

Three measurements were taken for each complex, and the average magnetic moment of the three was used.

Table S2: Evans measurements for complex 3.

\begin{tabular}{|c|c|}
\hline Measurement & $\boldsymbol{\mu}_{\text {eff }}\left(\boldsymbol{\mu}_{\mathrm{B}}\right)$ \\
\hline 1 & 1.98 \\
\hline 2 & 2.06 \\
\hline 3 & 2.09 \\
\hline Average & $2.0 \pm 0.1$ \\
\hline
\end{tabular}




\section{EPR Spectra}

The magnitude of the coupling constants associated with the hyperfine splitting patterns of the $\mathrm{g}=3$ and 1.9 absorptions can be easily estimated from the peak-to-peak separation of the individual lines i.e., 590(10) $\mathrm{MHz}$ and 230(10) MHz. In contrast, the hyperfine splitting of the $\mathrm{g}=2.2$ absorption, as well as the distribution in the A and $g$ values, could be obtained only from spectral simulations. The progressive broadening of the absorptions belonging to a particular hyperfine splitting pattern originates from combined effects of a distribution the hyperfine coupling constants, $\sigma\left(\mathrm{A}_{\xi}\right)$, and $g$ values, $\sigma\left(\mathrm{g}_{\xi}\right)$. Simulations of the X-band spectrum shown in Figure 2 used a spin-Hamiltonian model with hyperfine coupling accounted for with first order perturbation of the electronic Zeeman effect and provided: $\mathrm{g}_{\mathrm{x}}=$ $3.068, \mathrm{~g}_{\mathrm{y}}=2.214, \mathrm{~g}_{\mathrm{z}}=1.955 ; \sigma\left(\mathrm{g}_{\mathrm{x}}\right)=0.03, \sigma\left(\mathrm{g}_{\mathrm{y}}\right)=\sigma\left(\mathrm{g}_{\mathrm{z}}\right)=0.00, \mathrm{~A}_{\mathrm{x}}=587 \mathrm{MHz}, \mathrm{A}_{\mathrm{y}}=280 \mathrm{MHz}, \mathrm{A}_{\mathrm{z}}=230$ $\mathrm{MHz}, \sigma\left(\mathrm{A}_{\mathrm{x}}\right)=25 \mathrm{MHz}, \sigma\left(\mathrm{A}_{\mathrm{y}}\right)=10 \mathrm{MHz}, \sigma\left(\mathrm{A}_{\mathrm{z}}\right)=5 \mathrm{MHz}$, with an intrinsic Lorentzian linewidth $\Gamma=15$ $\mathrm{G}$. The difference in the $\mathrm{X}$-band $\mathrm{g}$ values when compared with those of the high frequency spectra is an artifact that originates from the use when evaluating the hyperfine coupling of perturbation theory (see Figure S15).

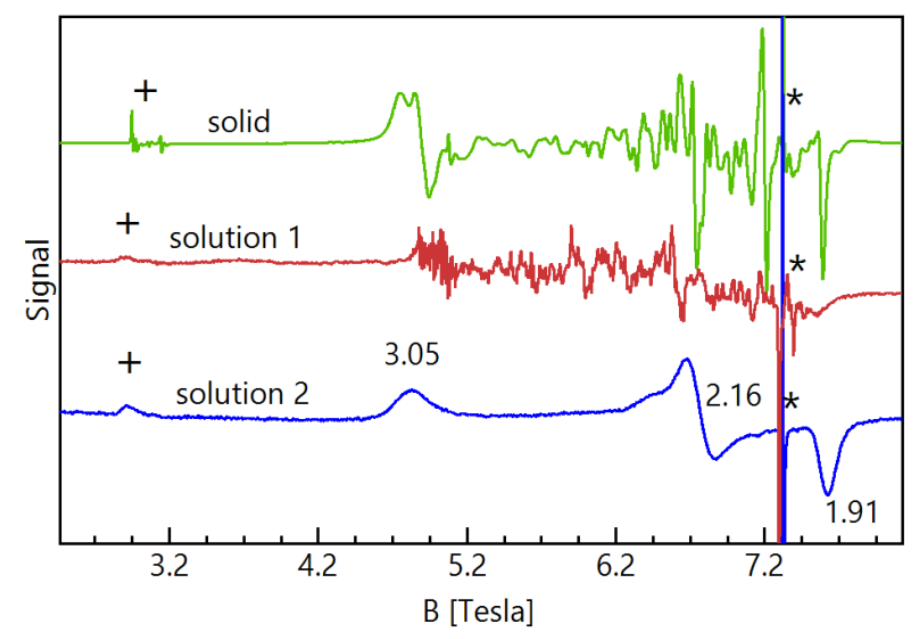

Figure S10. High-frequency EPR spectra recorded at $203.2 \mathrm{GHz}, 10 \mathrm{~K}$ for two frozen toluene solution and a ground solid samples of $\mathbf{3}$. While the $(+)$ sign labels resonances that originate from surface adsorbed molecular oxygen, $(*)$ labels $g=2.00$. The intense and narrow resonance associated with $g=2$ originates from a radical impurity. 


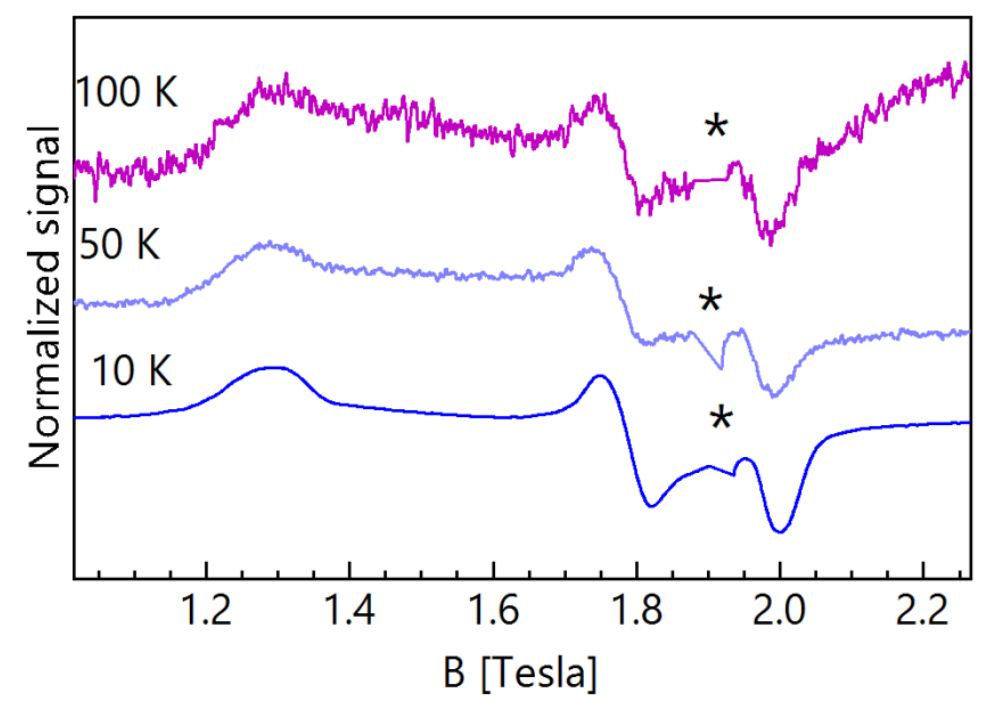

Figure S11. Temperature dependent spectra recorded at $52 \mathrm{GHz}$ for a frozen toluene solution of $\mathbf{3}$. The spectra are normalized. The $(*)$ denotes the position of $g=2.00$. For sake of clarity the intense, radical impurity - based signal was removed from the spectra.

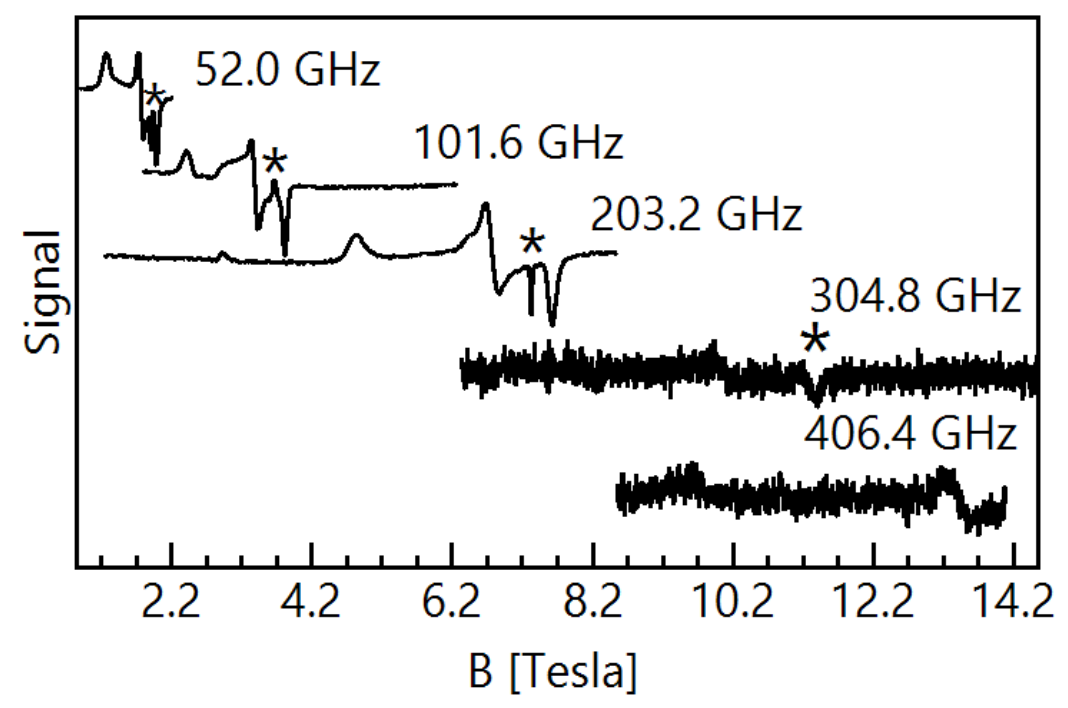

Figure S12. Variable-frequency EPR spectra recorded at $10 \mathrm{~K}$ for a frozen toluene solution of 3 . The $(*)$ denotes the position of $g=2.00$. For sake of clarity the intense, radical impurity - based signal was removed from the spectra. 


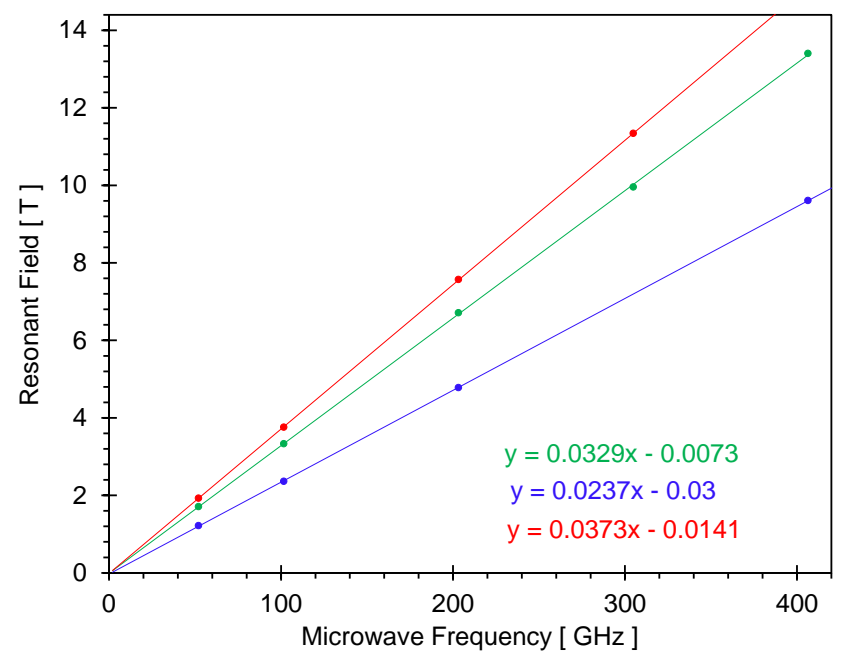

Figure S13. Frequency-dependence of the resonant field values of the observed resonances. The linear fits obtained for these resonances are listed as an inset and yield the following effective $g$ values: 2.171 (green), 3.014 (blue), and 1.915(red).

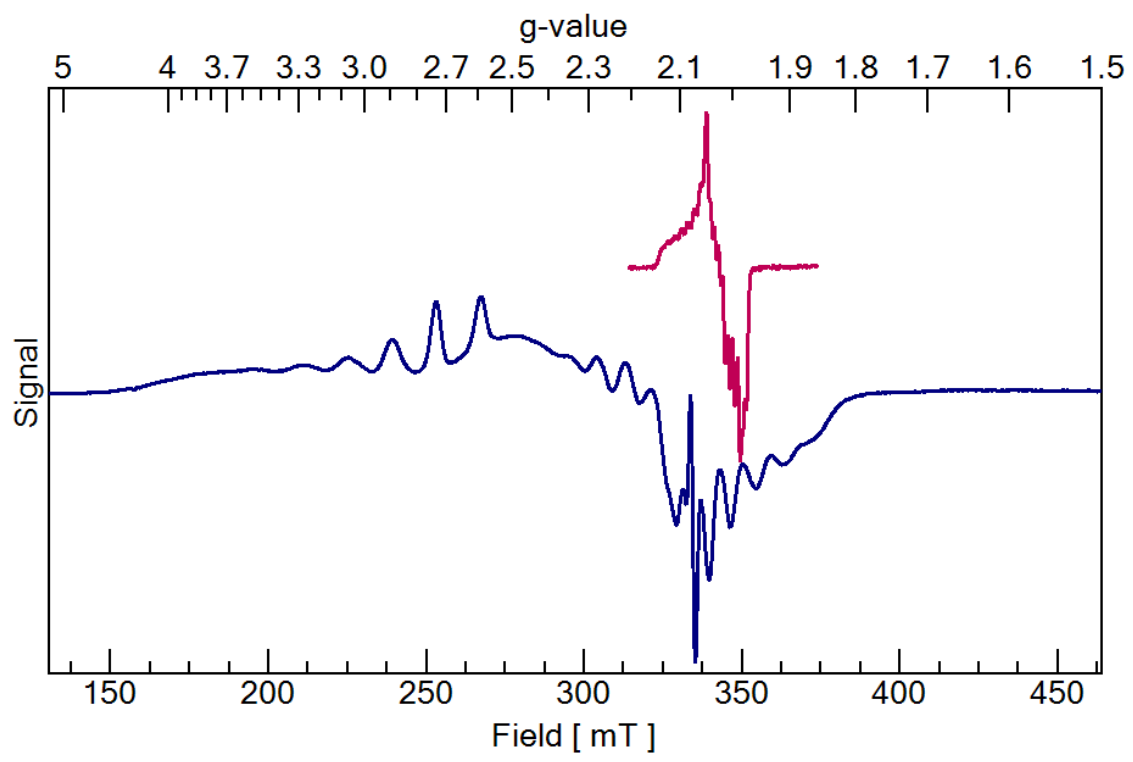

Figure S14. X-band spectra recorded at $20 \mathrm{~K}$ for a frozen THF solution of [(corrole)Co]Cl (top) and frozen toluene solution of $\mathbf{3}$ (bottom). These spectra illustrate the difference between a ligand-based spin density i.e., cobalt coordinated corrole - radical, and a metal based spin density, 3. Interestingly, both compounds enclose a formal cobalt(IV) site. However the corrole complex is not believed to contain a genuine $\mathrm{Co}^{4+}$ site but rather a $S=0$, low-spin $\mathrm{Co}(\mathrm{III})$ center. ${ }^{10}$ 


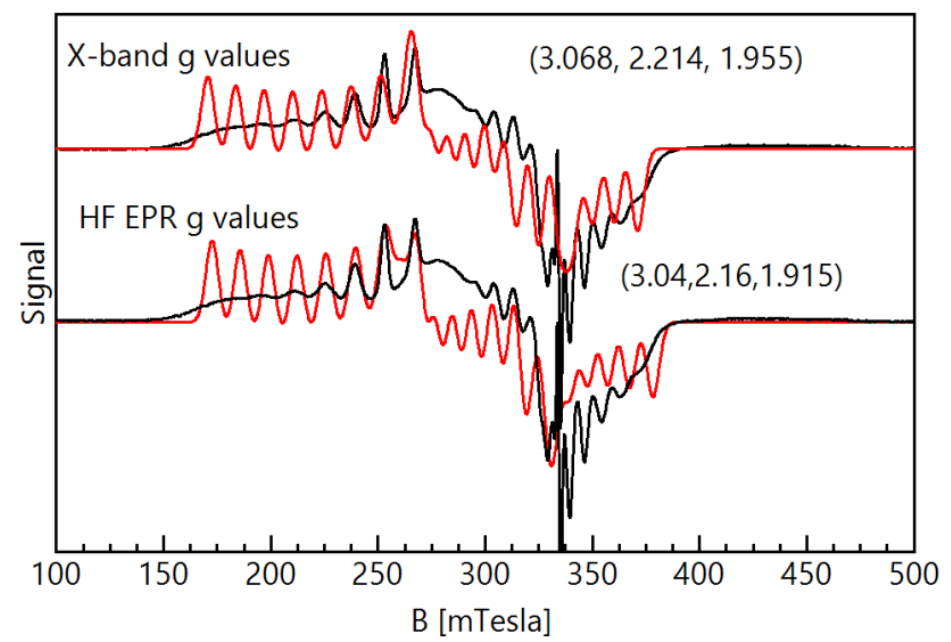

Figure S15. Simulations of the $20 \mathrm{~K}, \mathrm{X}$-band spectrum recorded for a frozen toluene solution of $\mathbf{3}$ obtained from the full diagonalization of the $16 \times 16,\{(S=1 / 2) \otimes(I=7 / 2)\}$ complex spinHamiltonian $^{11}$ and the g-values determined from the analysis of the high-frequency EPR spectra (bottom) and those obtained from the simulations of the X-band spectrum obtained using a first order perturbation treatment of the hyperfine coupling. Comparison of the simulated spectra shown in red reveals that indeed, the higher g-values obtained from the simulations of the X-band spectra using a perturbative approach when compared with the values determined from the high-frequency EPR spectra is an artifact of the perturbative treatment of the hyperfine interaction.

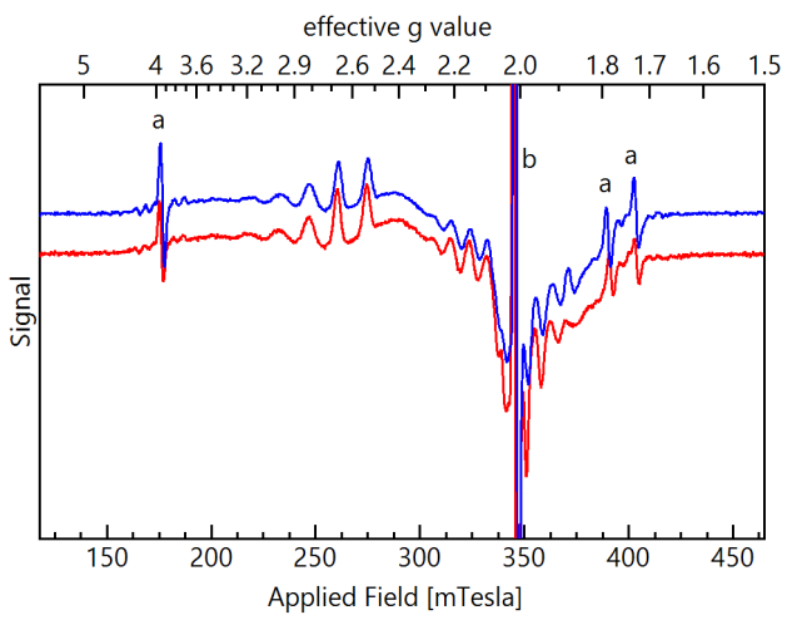

Figure S16. X-band EPR spectra recorded at $10 \mathrm{~K}$ for a ${ }^{13} \mathrm{C}$ labeled (blue) and unlabeled (red) $5 \mathrm{mM}$ solution of 3 . While the spectral features indicated by (a) originate from contaminants of the dielectric resonator, that observed at $\mathrm{g}=2$ labeled using (b) arises from a radical-based impurity. 
Our attempts to estimate the magnitude of the ${ }^{1} \mathrm{H}$ superhyperfine couplings from the simulations of the continuous-wave X-band EPR spectra were unsuccessful. Consequently, we have performed a series of pulsed EPR measurements on deuterated toluene solutions of 3. Inspection of Figure S17 that shows a typical Hyperfine Sublevel Correlation spectrum (HYSCORE) recorded at X-band reveals two distinct sets of resonances one that is very intense and relatively narrow centered at $\sim 2 \mathrm{MHz}$ and another set that is considerably broader found in the $15-20 \mathrm{MHz}$ region of the spectrum. Based on their values we assign the first set of resonance to the hyperfine coupling with the $I=1$ nuclear spins of ${ }^{2} \mathrm{D}$ nuclei incorporated in the deuterated toluene solvent and the other to the interaction with the $I=1 / 2$ of the ${ }^{1} \mathrm{H}$ nuclei of the cobalt-coordinated ligands.
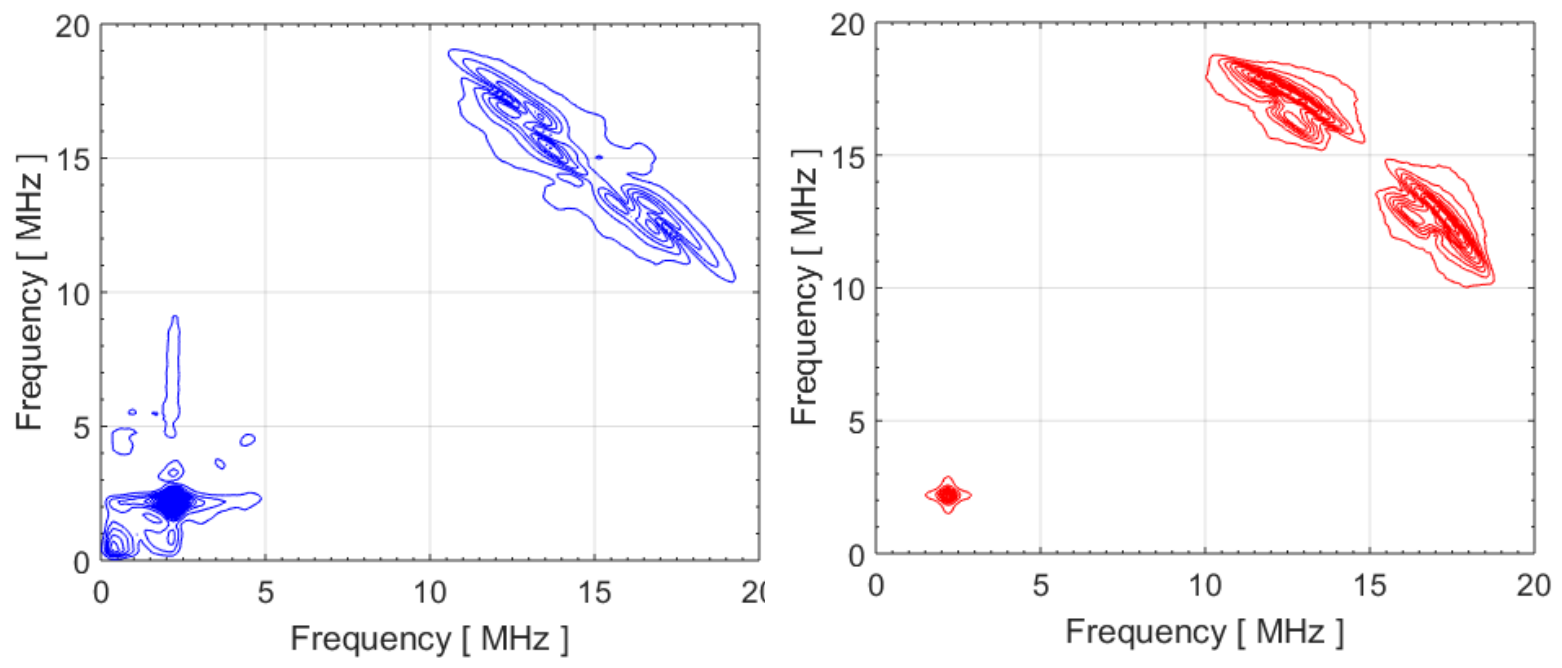

Figure S17. Left: Typical X-band HYSCORE spectrum recorded at $10 \mathrm{~K}$ for a $5 \mathrm{mM}$ deuterated toluene solution of 3. The experimental conditions for the current spectrum are: microwave frequency, $v=9.70 \mathrm{GHz}$; temperature, shot repetition time, $499.8 \mathrm{Os} ; \mathrm{t}_{\mathrm{a}^{2}}=16 \mathrm{~ns}$; delay between the first and second microwave pulse, $\tau=200 \mathrm{~ns}$; magnetic field $340 \mathrm{mT}(\mathrm{g}=2.004)$. Right: Simulated HYSCORE spectrum obtained considering the coupling of the $S=1 / 2$ electronic spin to three distinct ${ }^{1} \mathrm{H}, \mathrm{I}=1 / 2$ nuclei characterized by anisotropic tensors such that $A_{x, y, z}(1)=\{-3,-1,-3\}$ $\mathrm{MHz}, \mathrm{A}_{\mathrm{x}, \mathrm{y}, \mathrm{z}}(2)=\{1,1,9\} \mathrm{MHz}, \mathrm{A}_{\mathrm{x}, \mathrm{y}, \mathrm{z}}(3)=\{3,0,2\} \mathrm{MHz}$ and $\mathrm{a}^{2} \mathrm{H}, \mathrm{I}=1$ with an isotropic HFC tensor $\mathrm{A}_{\text {iso }}=0.05 \mathrm{MHz}$. 


\section{Computational Details}

DFT $^{12}$ calculations were carried out using Revision D01 of Gaussian $09 .{ }^{13}$ Geometry optimizations were performed at the B3LYP/6-31G(d) level of theory. ${ }^{14}$ Reoptimization of the lowest energy spin state, 3 doublet, with the 6-311G(d) basis set did not improve the bond lengths and characterization of the wavefunction was the same based on Mulliken spin densites (Table S2). Therefore, our analysis in the manuscript focuses on the double-zeta results. All optimized structures were confirmed to have stable wavefunctions ${ }^{15}$ and to be minima on the potential energy surface ${ }^{16}$ Cartesian coordinates, frequencies, and thermodynamics for each species may be found in Tables S6-S8.

Table S3. Comparison of Co-L bond lengths $(\AA)$ and Mulliken spin densities.

\begin{tabular}{|c|c|c|c|}
\hline & Exp. & $\begin{array}{c}\text { B3LYP } \\
\mathbf{6 - 3 1 G ( d )}\end{array}$ & $\begin{array}{c}\text { B3LYP } \\
\mathbf{6 - 3 1 1 G ( d )}\end{array}$ \\
\hline Co-C & 1.773 & 1.823 & 1.827 \\
\hline Co-O & 1.765 & 1.759 & 1.768 \\
\hline Co spin & - & 1.77 & 1.73 \\
\hline C spin & - & -0.68 & -0.67 \\
\hline O spin & - & 0.05 & 0.07 \\
\hline
\end{tabular}

The electronic structure of 3 was re-evaluated at the B3LYP/6-31G(d) optimized geometry using (i) OPBE,${ }^{17}$ a functional that excels at predicting spin state energies, ${ }^{18}$ and (ii) $\omega \mathrm{B} 97-\mathrm{XD},{ }^{19}$ a long-range corrected functional. As Table $\mathrm{S} 4$ demonstrates, the $\mathrm{Co}^{\mathrm{III}}-\mathrm{C}^{\cdot}$ vs. $\mathrm{Co}^{\mathrm{IV}}=\mathrm{C}$ character, which is ideally 2.0 and -1.0 for the former and 1.0 and 0.0 for the latter, is sensitive to the functional choice. OPBE predicts the most $\mathrm{Co}^{\mathrm{IV}}=\mathrm{C}$ character and shows the least spin contamination, as tracked by the $\mathrm{S}^{2}$ value after projection of the first spin contaminant, and $\omega \mathrm{B} 97-\mathrm{XD}$ predicts the most $\mathrm{Co}^{\mathrm{III}}-\mathrm{C}^{*}$ character. Both the amount of spin contamination and the $\mathrm{Co}^{\mathrm{IV}}=\mathrm{C}$ character is correlated with the amount of explicit HartreeFock exchange in each functional, reminiscent of spin state energies (see Ref 12 in manuscript). To benchmark our expectations for a true $\mathrm{M}^{\mathrm{IV}}=\mathrm{C}$ system, we optimized the hypothetical species replacing Co with $\mathrm{Rh}$ at the B3LYP/SDD/6-31G(d) level of theory. ${ }^{20}$ This complex has an optimized $\mathrm{Rh}-\mathrm{C}$ bond length of $1.858 \AA$ that is shorter than the dirhodium carbenes that are known experimentally (see Ref 9 in manuscript). As shown in Table S4, none of these wavefunctions suffer from spin contamination, yet the amount of spin density on the carbene $\mathrm{C}$ varies from -0.07 for OPBE to -0.25 for $\omega \mathrm{B} 97-\mathrm{XD}$. Thus, even in this ideal alkylidene system, spin polarization can place up to $\sim 0.3$ electrons worth of spin on the neighboring carbene $\mathrm{C}$. While a definitive answer would require multireference techniques (e.g. CASSCF) that are not feasible for this sized system, we believe the relatively small spin contaminations, comparison to the hypothetical $\mathrm{Rh}$ complex, and bond elongation from the Co doublet to quartet state allow us to conclude that there is significant $\pi$-bonding between Co and the diphenylcarbene.

Table S4. Comparison of Mulliken spin densities for $\mathbf{3}$ with different functionals and $\mathbf{3}_{\mathbf{R h}}$.

\begin{tabular}{|c|c|c|c|c|c|c|}
\hline & \multicolumn{3}{|c|}{ 3 } & \multicolumn{3}{c|}{$\mathbf{3}_{\mathbf{R h}}$} \\
\hline & B3LYP & OPBE & $\boldsymbol{\omega B 9 7 - X D}$ & $\mathbf{B 3 L Y P}$ & $\mathbf{O P B E}$ & $\boldsymbol{\omega B 9 7 - X D}$ \\
\hline M spin & 1.77 & 1.42 & 1.89 & 0.91 & 0.78 & 1.02 \\
\hline C spin & -0.68 & -0.44 & -0.82 & -0.16 & -0.07 & -0.25 \\
\hline O spin & 0.05 & 0.07 & 0.05 & 0.12 & 0.12 & 0.12 \\
\hline $\mathrm{S}^{2}$ & 0.88 & 0.77 & 0.99 & 0.75 & 0.75 & 0.75 \\
\hline
\end{tabular}


To further validate the electronic structure of 3, we simulated the EPR parameters with ORCA. ${ }^{21}$ A summary of the predicted hyperfine couplings may be found in Table S5. The simulated spectra based on these values are shown in Figure S18, and visualization of the directionality of the tensor components may be seen in Figure S19. Inspection of Figure S20 shows that the lowest 1-electron excitation corresponds to the promotion of a $\beta$, spin-down electron from the doubly-occupied $\mathrm{d} x^{2}-y^{2}$ orbital to the singly-occupied $\mathrm{d} x y$ orbital. Interestingly, the two orbital states corresponding to the ground and first excited orbital states are mixed by the $z$ component of the spin-orbit operator $\widehat{\mathrm{H}}_{\mathrm{SO}}=\lambda \overrightarrow{\mathbf{L}} \cdot \overrightarrow{\mathbf{S}}$. Consequently, the largest orbital contributions to the $\mathrm{g}$ and $\mathrm{A}\left({ }^{59} \mathrm{Co}\right)$ tensors are expected along the $\mathrm{z}$ direction along the $\mathrm{Co}-\mathrm{C}$ bond.

Table S5. Simulated hyperfine coupling tensor components at the B3LYP/6-31G(d) level within the diphenylcarbene Co portion of the complex. $\mathrm{FC}=$ Fermi contact, $\mathrm{SD}=$ spin dipole. ${ }^{1} \mathrm{H}$ values for the ortho, para, and meta substituents are averaged over both phenyl rings.

\begin{tabular}{|l|c|c|c|c|c|c|c|}
\hline & $\mathbf{A}_{\text {FC }}$ & \multicolumn{3}{|c|}{$\mathbf{A}_{\text {SD }}$} & \multicolumn{3}{c|}{$\mathbf{A}_{\mathbf{F C}+\text { SD }}$} \\
\hline${ }^{59} \mathrm{Co}$ & +368 & -108 & -76 & 185 & 260 & 292 & 553 \\
\hline${ }^{13} \mathrm{C}^{a}$ & -144 & -68 & 27 & 41 & -212 & 27 & 41 \\
\hline${ }^{1} \mathrm{H}_{\text {ortho }}$ & 8.3 & -7.2 & -1.8 & 9.0 & 1.1 & 6.5 & 17.3 \\
\hline${ }^{1}$ & 8.1 & -4.0 & 0.0 & 4.0 & 4.1 & 8.1 & 12.1 \\
\hline${ }^{1} \mathrm{H}_{\text {meta }}$ & -4.2 & -1.6 & 0.3 & 1.3 & -5.8 & -3.9 & -2.9 \\
\hline
\end{tabular}

a. $\mathrm{C}$ in diphenylcarbene bound to Co.

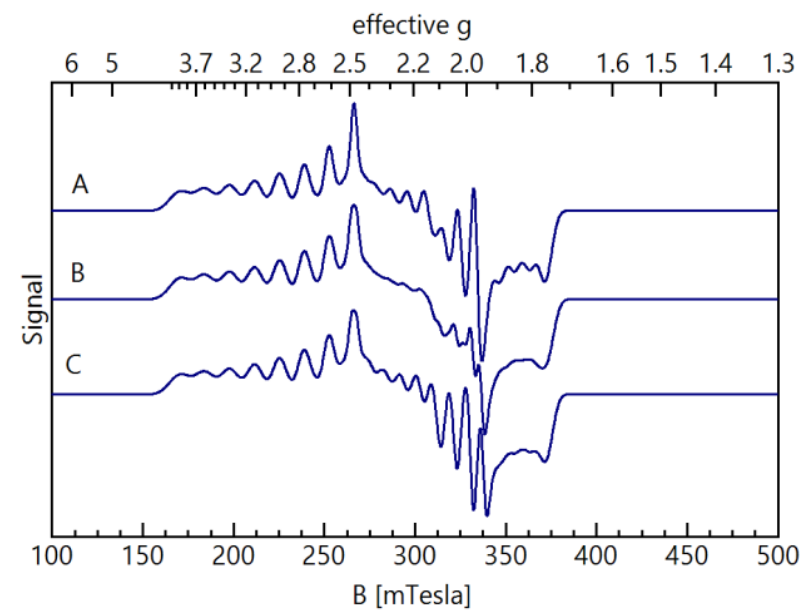

Figure S18. (A) Simulation of the X-band spectrum shown in Figure 2; (B) Simulation of the X-band spectrum shown in Figure 2 that also includes a $I=1 / 2,{ }^{13} \mathrm{C}$ nuclei with an isotropic HFC tensor such that $\mathrm{A}_{\text {iso }}=-144 \mathrm{MHz}$ i.e., the DFT-predicted value; (C) Simulation of the X-band spectrum shown in Figure 2 that also includes a $I=1 / 2,{ }^{13} \mathrm{C}$ nuclei with a $\mathrm{HFC}$ tensor such that $\mathrm{A}_{\mathrm{x}}=-103 \mathrm{MHz}, \mathrm{A}_{\mathrm{y}}=-212 \mathrm{MHz}$, and $A_{z}=-103 \mathrm{MHz}$, see Figure X3. These values were obtained from the sum of the DFT-predicted, B3LYP/6-31G(d), Fermi-contact and spin-dipolar contributions to the HFC tensor. 


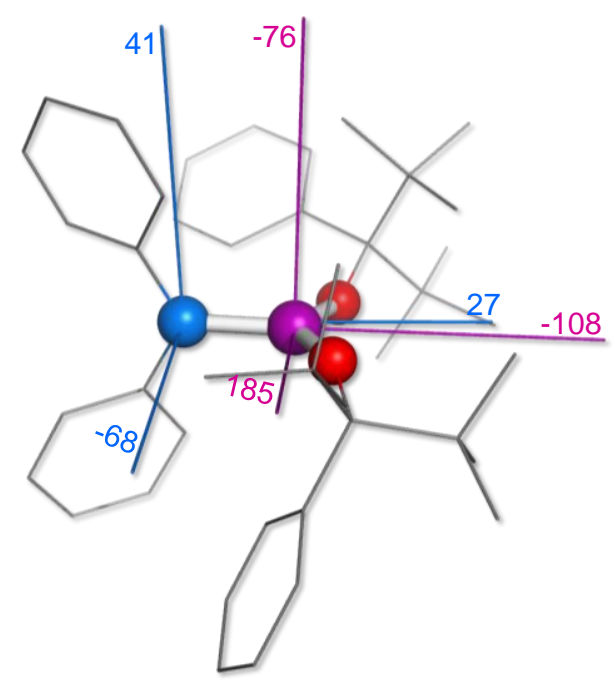

Figure S19. Relative orientations of the spin-dipolar components of the HFC tensors of the ${ }^{13} \mathrm{C}$ shown in blue and ${ }^{59} \mathrm{Co}$ shown in purple predicted at B3LYP/6-31G(d) level. The predicted values of the principal tensor components are shown near their respective axis and are expressed in MHz. The Fermi-contact values of the HFC tensor predicted for the ${ }^{13} \mathrm{C}$ nucleus is $-144 \mathrm{MHz}$ and respectively, $+368 \mathrm{MHz}$ for the ${ }^{59}$ Co nucleus, see Table S5. Analysis of the TD-DFT excitations suggests that the $\mathrm{g}$ tensor is oriented such that its largest component, $\mathrm{g}_{\max } \sim 3$, is found along the $\mathrm{Co}-\mathrm{C}$ axis and that the intermediate value, $\mathrm{g}_{\text {mid }} \sim 2.2$, is perpendicular to the plane defined by the Co-O bonds, see Figure S20. 


$\begin{gathered}\text { Excitation Energy } \\ (\mathbf{e V})\end{gathered}$
NTDO

Figure S20. Isosurface plots (iso $=0.05 \mathrm{au}$ ) of the TD-DFT derived Natural Transition Donor (NTDO) and Acceptor (NTAO) orbitals ${ }^{22}$ involved in the lowest three single-electron excitations. We define the $\mathrm{z}$ axis to contain the Co-C bond, the yz plane to contain the ipso carbons of diphenylcarbene, and the $\mathrm{xy}$ plane to contain the $\mathrm{Co}-\mathrm{O}_{\text {alkoxide }}$ bonds. These transitions are consistent with either an intermediate-spin Co ${ }^{\text {III }}$ ion $\left|\mathrm{d}_{\mathrm{yz}}{ }^{2} \mathrm{~d}_{\mathrm{x} 2-\mathrm{y} 2}{ }^{2} \mathrm{~d}_{\mathrm{xy}}{ }^{1} \mathrm{~d}_{\mathrm{xz}}{ }^{1} \mathrm{~d}_{\mathrm{z} 2}{ }^{0}\right|$ or a low-spin $\mathrm{Co}^{\mathrm{IV}}$ ion $\left|\mathrm{d}_{\mathrm{yz}}{ }^{2} \mathrm{~d}_{\mathrm{x} 2-\mathrm{y} 2}{ }^{2} \mathrm{~d}_{\mathrm{xy}}{ }^{1} \mathrm{~d}_{\mathrm{xz}}{ }^{0} \mathrm{~d}_{\mathrm{z} 2}{ }^{0}\right|$. 
Table S6. Cartesian coordinates of optimized structures (in $\AA$ ).

\begin{tabular}{|c|c|c|c|}
\hline \\
\hline \multicolumn{4}{|c|}{$\begin{array}{lll} & & \\
3 \text { doublet } & & \\
6-31 \mathrm{G}(\mathrm{d}) & & \\
---1.714704 & 0.085729\end{array}$} \\
\hline \multicolumn{4}{|c|}{$\begin{array}{llrl}0 & 0.706837 & -1.714704 & 0.085729 \\
0 & 1.052304 & 1.508411 & 0.385216\end{array}$} \\
\hline \multicolumn{4}{|c|}{-2} \\
\hline $\mathrm{C}$ & 0.320269 & -3.615842 & -1.385070 \\
\hline-2.317221 & 2.601484 & -2.317221 & -1.369193 \\
\hline \multicolumn{4}{|r|}{0.804716} \\
\hline \multicolumn{4}{|c|}{-4.688228} \\
\hline \multicolumn{4}{|c|}{-3.274243} \\
\hline \multicolumn{4}{|l|}{ C } \\
\hline \multicolumn{4}{|l|}{$\mathrm{C}$} \\
\hline $\mathrm{C}$ & 3.313600 & -1.121708 & -0.691756 \\
\hline \multicolumn{4}{|l|}{$\mathrm{C}$} \\
\hline \multicolumn{4}{|c|}{-5.224604} \\
\hline \multicolumn{4}{|c|}{-3.155111} \\
\hline \multicolumn{4}{|c|}{-0.267006} \\
\hline \multicolumn{4}{|l|}{$\mathrm{H}$} \\
\hline \multicolumn{4}{|c|}{-1} \\
\hline $\mathrm{H}$ & -1.357128 & -2.469102 & -0.711228 \\
\hline $\mathrm{H}$ & 3.387702 & -4.234960 & -2.192710 \\
\hline $\mathrm{H}$ & 4.462483 & -2.856523 & -2.320221 \\
\hline $\mathrm{H}$ & 4.255848 & -3.651822 & -0.764665 \\
\hline $\mathrm{H}$ & 2.874984 & -1.244081 & -3.243477 \\
\hline $\mathrm{H}$ & 1.745809 & -2.596883 & -3.390680 \\
\hline $\mathrm{H}$ & 1.233196 & -1.108031 & -2.599312 \\
\hline $\mathrm{H}$ & 3.762966 & -1.373483 & 0.268605 \\
\hline $\mathrm{H}$ & 4.120351 & -0.775849 & -1.349094 \\
\hline $\mathrm{H}$ & 2.647507 & -0.274904 & -0.530609 \\
\hline $\mathrm{H}$ & 0.555732 & -4.626919 & 2.470846 \\
\hline $\mathrm{H}$ & 0.066250 & -2.972661 & 2.078186 \\
\hline $\mathrm{H}$ & -0.461748 & -4.324583 & 1.057335 \\
\hline $\mathrm{H}$ & 3.011701 & -5.269560 & -0.155706 \\
\hline $\mathrm{H}$ & 2.362649 & -5.734065 & 1.411623 \\
\hline $\mathrm{H}$ & 1.329782 & -5.802977 & -0.014833 \\
\hline $\mathrm{H}$ & 2.478714 & -2.117211 & 1.976681 \\
\hline $\mathrm{H}$ & 2.746901 & -3.716258 & 2.678408 \\
\hline $\mathrm{H}$ & 3.732435 & -3.192529 & 1.318601 \\
\hline C & -1.612485 & -5.000486 & -2.950302 \\
\hline $\mathrm{H}$ & 0.056776 & -6.185265 & -3.631199 \\
\hline $\mathrm{H}$ & -3.034548 & -3.651659 & -2.052081 \\
\hline $\mathrm{H}$ & -2.349324 & -5.529369 & -3.549118 \\
\hline $\mathrm{C}$ & 1.249693 & 2.710887 & 1.112362 \\
\hline C & 0.048124 & 2.979479 & 2.068392 \\
\hline C & 2.557026 & 2.422377 & 2.035401 \\
\hline $\mathrm{C}$ & 1.365373 & 3.866214 & -0.030294 \\
\hline C & -0.128097 & 4.189768 & 2.765324 \\
\hline $\mathrm{C}$ & -0.902780 & 1.981497 & 2.308935 \\
\hline $\mathrm{C}$ & 2.840738 & 3.495890 & 3.112433 \\
\hline C & 2.335988 & 1.095833 & 2.801467 \\
\hline $\mathrm{C}$ & 3.842489 & 2.252216 & 1.198230 \\
\hline $\mathrm{C}$ & -0.058602 & 4.134111 & -0.578356 \\
\hline C & 1.961764 & 5.229729 & 0.391147 \\
\hline $\mathrm{C}$ & 2.239063 & 3.403872 & -1.228332 \\
\hline $\mathrm{C}$ & -1.204186 & 4.390659 & 3.630129 \\
\hline $\mathrm{H}$ & 0.582520 & 4.996069 & 2.655885 \\
\hline C & -1.981436 & 2.169830 & 3.174956 \\
\hline $\mathrm{H}$ & -0.801664 & 1.033030 & 1.804541 \\
\hline $\mathrm{H}$ & 2.066755 & 3.521459 & 3.883110 \\
\hline
\end{tabular}

$\begin{array}{rrrr}\mathrm{H} & 3.785492 & 3.242419 & 3.609125 \\ \mathrm{H} & 2.953639 & 4.503336 & 2.707162 \\ \mathrm{H} & 3.177820 & 0.930350 & 3.484460 \\ \mathrm{H} & 1.422486 & 1.117240 & 3.403198 \\ \mathrm{H} & 2.283715 & 0.240355 & 2.124701 \\ \mathrm{H} & 4.225205 & 3.205813 & 0.822722 \\ \mathrm{H} & 4.627833 & 1.821858 & 1.831927 \\ \mathrm{H} & 3.692519 & 1.579197 & 0.352219 \\ \mathrm{H} & -0.000469 & 4.804745 & -1.444175 \\ \mathrm{H} & -0.544468 & 3.210376 & -0.903049 \\ \mathrm{H} & -0.704488 & 4.607863 & 0.165277 \\ \mathrm{H} & 2.995354 & 5.146679 & 0.736760 \\ \mathrm{H} & 1.975683 & 5.881109 & -0.492126 \\ \mathrm{H} & 1.381674 & 5.755762 & 1.151162 \\ \mathrm{H} & 2.051829 & 2.366792 & -1.502167 \\ \mathrm{H} & 2.015085 & 4.035943 & -2.096059 \\ \mathrm{H} & 3.307396 & 3.506332 & -1.029012 \\ \mathrm{C} & -2.143898 & 3.381755 & 3.840558 \\ \mathrm{H} & -1.301100 & 5.344496 & 4.142967 \\ \mathrm{H} & -2.692868 & 1.361247 & 3.317585 \\ \mathrm{H} & -2.982763 & 3.537931 & 4.513714 \\ \mathrm{C} & -1.319906 & 0.153767 & -0.898551 \\ \mathrm{C} & -2.514050 & -0.051314 & -0.083613 \\ \mathrm{C} & -2.505790 & -0.932680 & 1.024204 \\ \mathrm{C} & -3.705887 & 0.671786 & -0.335513 \\ \mathrm{C} & -3.640204 & -1.112998 & 1.809173 \\ \mathrm{H} & -1.605414 & -1.498050 & 1.243844 \\ \mathrm{C} & -4.830899 & 0.501960 & 0.464813 \\ \mathrm{H} & -3.729539 & 1.383552 & -1.153930 \\ \mathrm{C} & -4.809416 & -0.397244 & 1.534803 \\ \mathrm{H} & -3.611173 & -1.814328 & 2.638697 \\ \mathrm{H} & -5.729336 & 1.076115 & 0.254566 \\ \mathrm{H} & -5.692708 & -0.533831 & 2.152564 \\ \mathrm{C} \mathrm{H} & -1.580871 & 1.125431 & -6.177534 \\ \mathrm{C} & -1.404894 & 0.445786 & -2.323008 \\ \mathrm{C} & -2.470497 & -0.057105 & -3.111725 \\ \mathrm{C} & -0.397884 & 1.183554 & -2.987502 \\ \mathrm{C} & -2.527510 & 0.183618 & -4.480225 \\ \mathrm{H} & -3.239578 & -0.659834 & -2.641287 \\ \mathrm{C} & -0.467063 & 1.434752 & -4.353029 \\ \mathrm{H} & 0.429208 & 1.580885 & -2.412015 \\ \mathrm{H} & -3.350661 & -0.223587 & -5.061318 \\ & 0.314654 & 2.019512 & -4.830087 \\ & -0.009117 & -0.076509 \\ & & \end{array}$

3 quartet

\begin{tabular}{lrrr}
\multicolumn{4}{l}{-------} \\
O & 0.938627 & -1.516242 & -0.541935 \\
O & 0.986007 & 1.500456 & 0.531978 \\
C & 1.517989 & -2.759557 & -0.792353 \\
C & 0.417320 & -3.736083 & -1.319484 \\
C & 2.617914 & -2.480486 & -1.968002 \\
C & 2.051847 & -3.313625 & 0.634489 \\
C & 0.672816 & -5.037858 & -1.788228 \\
C & -0.918499 & -3.314879 & -1.340460 \\
C & 3.691107 & -3.569018 & -2.192871 \\
C & 1.859094 & -2.286495 & -3.304349 \\
C & 3.386860 & -1.159363 & -1.719394 \\
C & 0.889338 & -3.205613 & 1.651498
\end{tabular}




\begin{tabular}{|c|c|c|c|}
\hline $\mathrm{C}$ & 2.505947 & -4.792391 & 0.663731 \\
\hline & .209898 & -2.459341 & 89508 \\
\hline & -0.351454 & -5.864786 & -2.2 \\
\hline & 1.680267 & -5.430590 & -1.7 \\
\hline & -1.950483 & -4.137404 & -1.7957 \\
\hline & -1.141511 & -2.317664 & -0.99 \\
\hline & 3.275141 & -4.544310 & -2.4 \\
\hline & 4.326739 & -3.264613 & -3.0 \\
\hline & 4.349201 & -3.693684 & -1 \\
\hline & 2.554624 & -1.929522 & -4.0 \\
\hline & 1.408856 & -3.213442 & -3.6 \\
\hline & 1.062119 & -1.543345 & -3.1 \\
\hline & 4.071785 & -1.215506 & -0.8 \\
\hline & 3. & -0.927547 & -2.6 \\
\hline & 2.70 & -0.323721 & -1 \\
\hline & 1.192 & -3.6574 & \\
\hline & 0.627246 & -2.162633 & \\
\hline & -0.006719 & -3.729846 & 1.3 \\
\hline & 3.27 & -5.025720 & $-0.0^{\circ}$ \\
\hline & 2.92 & -5.006845 & 1.6 \\
\hline & 1. & -5 . & 0. \\
\hline & 2. & -1 & \\
\hline & 3 & -2 . & \\
\hline $\mathrm{H}$ & 4. & -2.651982 & 0.6 \\
\hline & -1. & -5.422001 & -2.2 \\
\hline & -0.1 & -6.862983 & -2.60 \\
\hline & -2. & -3.76 & -1.7 \\
\hline H & -2.4 & -6.0 & -2 \\
\hline $\mathrm{C}$ & 1.3 & 2.6 & \\
\hline $\mathrm{C}$ & 0. & 3.13 & \\
\hline $\mathrm{C}$ & 2.4 & 2.21 & 2 . \\
\hline C & 1.70 & 3.75 & 0.0 \\
\hline C & 0.0 & 4.37 & 2 . \\
\hline $\mathrm{C}$ & -1.0 & 2.29 & 2 . \\
\hline C & 2.8 & 2 & \\
\hline $\mathrm{C}$ & 1. & 1. & 3. \\
\hline $\mathrm{C}$ & 3. & 1.747269 & 1.5 \\
\hline $\mathrm{C}$ & 0.393551 & 4.313 & -0.5 \\
\hline C & 2.558063 & 4.967386 & 0 . \\
\hline $\mathrm{C}$ & 2.4 & 3.10 & -1.0 \\
\hline $\mathrm{C}$ & -1.1 & 7 & 3. \\
\hline $\mathrm{H}$ & 0. & 5 & \\
\hline $\mathrm{C}$ & -2.1 & 2.660 & 2.9 \\
\hline $\mathrm{H}$ & -1.010449 & 1.337460 & 1.6 \\
\hline $\mathrm{H}$ & 2.060680 & 3.5327 & 4.0 \\
\hline $\mathrm{H}$ & 3. & 2.87 & 3 . \\
\hline $\mathrm{H}$ & 3.2 & 421 & \\
\hline $\mathrm{H}$ & 2 . & 77 & \\
\hline $\mathrm{H}$ & 1.041083 & 1.260 & 3.6 \\
\hline $\mathrm{H}$ & 1.736161 & 0.151575 & 2.472 \\
\hline $\mathrm{H}$ & 4.325201 & 2.578952 & 1.1 \\
\hline $\mathrm{H}$ & 4.415337 & 1.245929 & 2.2 \\
\hline $\mathrm{H}$ & 27270 & 1.035202 & 0.7 \\
\hline $\mathrm{H}$ & 0.6 & 4.872 & -1.4 \\
\hline $\mathrm{H}$ & -0.297522 & 3.506060 & -0.77298 \\
\hline $\mathrm{H}$ & -0.131574 & 4.990948 & 0.16645 \\
\hline $\mathrm{H}$ & 3.566340 & 4.674132 & 0.85184 \\
\hline $\mathrm{H}$ & 2.668797 & 5.649703 & -0.3057 \\
\hline $\mathrm{H}$ & 2.111366 & 5.549705 & 1.35533 \\
\hline $\mathrm{H}$ & 1.928850 & 2.281933 & -1.52171 \\
\hline $\mathrm{H}$ & 2.656446 & 3.862573 & -1.84455 \\
\hline $\mathrm{H}$ & 3.459341 & 2.718680 & -0.77211 \\
\hline$C$ & -2.204170 & 3.893038 & 3.58375 \\
\hline
\end{tabular}

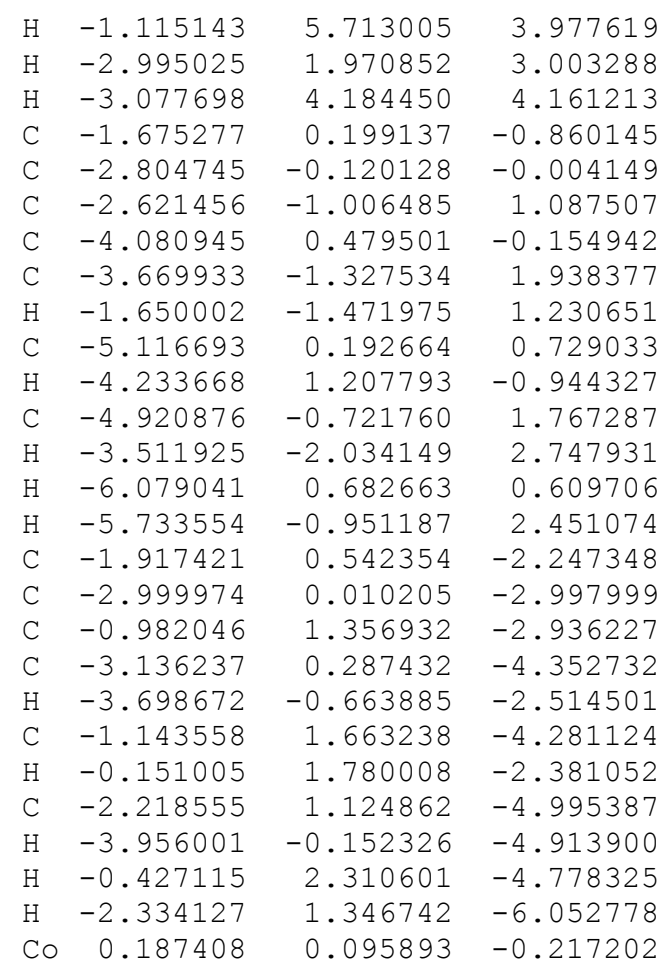

3 sextet

\begin{tabular}{rrrr}
\multicolumn{1}{c}{----1} & & \\
$\mathrm{O}$ & 0.901719 & -1.556803 & -0.511764 \\
$\mathrm{O}$ & 0.714406 & 1.464342 & 0.663988 \\
$\mathrm{C}$ & 1.577994 & -2.766916 & -0.806398 \\
$\mathrm{C}$ & 0.522120 & -3.749990 & -1.401315 \\
$\mathrm{C}$ & 2.680636 & -2.372396 & -1.935380 \\
$\mathrm{C}$ & 2.085797 & -3.337664 & 0.620990 \\
$\mathrm{C}$ & 0.859806 & -5.021465 & -1.899576 \\
$\mathrm{C}$ & -0.829254 & -3.382842 & -1.465230 \\
$\mathrm{C}$ & 3.824567 & -3.391651 & -2.130124 \\
$\mathrm{C}$ & 1.962496 & -2.198058 & -3.296839 \\
$\mathrm{C}$ & 3.356507 & -1.011787 & -1.637597 \\
$\mathrm{C}$ & 0.880316 & -3.340662 & 1.593790 \\
$\mathrm{C}$ & 2.621510 & -4.789449 & 0.605137 \\
$\mathrm{C}$ & 3.175990 & -2.449922 & 1.255945 \\
$\mathrm{C}$ & -0.104777 & -5.878831 & -2.430291 \\
$\mathrm{H}$ & 1.884241 & -5.366617 & -1.881018 \\
$\mathrm{C}$ & -1.798977 & -4.239710 & -1.990286 \\
$\mathrm{H}$ & -1.131537 & -2.408963 & -1.107876 \\
$\mathrm{H}$ & 3.475058 & -4.391541 & -2.393965 \\
$\mathrm{H}$ & 4.454369 & -3.051177 & -2.961271 \\
$\mathrm{H}$ & 4.470655 & -3.470537 & -1.251585 \\
$\mathrm{H}$ & 2.660486 & -1.759493 & -4.020293 \\
$\mathrm{H}$ & 1.609487 & -3.146528 & -3.708585 \\
$\mathrm{H}$ & 1.101437 & -1.527048 & -3.214313 \\
$\mathrm{H}$ & 3.895490 & -0.990055 & -0.690405 \\
$\mathrm{H}$ & 4.083352 & -0.801561 & -2.430954 \\
$\mathrm{H}$ & 2.636237 & -0.191035 & -1.640903 \\
$\mathrm{H}$ & 1.178456 & -3.809449 & 2.538862 \\
$\mathrm{H}$ & 0.538505 & -2.327693 & 1.821301 \\
$\mathrm{H}$ & 0.034233 & -3.906319 & 1.192355 \\
$\mathrm{H}$ & 3.442282 & -4.948314 & -0.097161 \\
$\mathrm{H}$ & 3.007230 & -5.020447 & 1.605561
\end{tabular}




\begin{tabular}{|c|c|c|c|}
\hline & 1.835333 & -5.516035 & \\
\hline & 890736 & -1.396100 & \\
\hline & .325267 & -2.756901 & 28 \\
\hline & & -2.545106 & \\
\hline & -1.444749 & -5.495222 & \\
\hline & 0.199875 & -6.852120 & -2.8069 \\
\hline & -2.835326 & -3.912854 & -2 \\
\hline & -2.196501 & -6.163465 & -2 . \\
\hline & 1.169895 & 2.6046 & \\
\hline & -0.04476 & $3.16^{\circ}$ & \\
\hline & 2.2831 & & \\
\hline & 1.613584 & 3.6518 & \\
\hline & 0.014 & 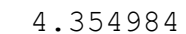 & \\
\hline & -1.26 & & \\
\hline & 2.7 & & \\
\hline & 1.6 & & \\
\hline & 3. & 1. & \\
\hline & 0 . & & -0 \\
\hline & 2.4604 & 35 & \\
\hline & 2.4 & 6 & -0 \\
\hline & -1 & & \\
\hline & 0 . & & \\
\hline & -2 & & \\
\hline & -1 & & \\
\hline & 1. & & \\
\hline & 3.5 & & \\
\hline & 3.1 & & \\
\hline & 2. & & \\
\hline & 0 . & & \\
\hline & 1.4 & & \\
\hline & 4 & & \\
\hline & 4.1 & & \\
\hline & 3. & & \\
\hline & 0.6 & & -1 \\
\hline & -0.3 & & -0 \\
\hline & -0.2 & 8 & \\
\hline & 3.4 & & \\
\hline & 2.6 & & -0 . \\
\hline & 1. & & \\
\hline & 1. & & -1 \\
\hline & 2.5 & & -1 \\
\hline & 3. & & -0 \\
\hline & -2.3 & & \\
\hline & -1.0 & & \\
\hline & -3 & 2.39 & 2. \\
\hline & -3 . & & \\
\hline & -1 & 0 . & -1 \\
\hline & -2 & -0 . & -0 . \\
\hline & -2.6 & -0.967230 & 0.98096 \\
\hline & -3.995 & 0.664817 & -0.19215 \\
\hline & -3.6 & -1.177850 & \\
\hline & -1.7 & -1.54 & \\
\hline & -5 & 0.45 & 0 . \\
\hline $\mathrm{H}$ & -4.1 & 1.4 & -0 . \\
\hline & -4.8879 & -0.467609 & 1.75662 \\
\hline & -3.564772 & -1.899823 & 2.68363 \\
\hline & -5 & 1.029183 & 104 \\
\hline & -5 & -0.628118 & \\
\hline & -1.810902 & 0.512117 & -2.39329 \\
\hline C & -2.986370 & 0.203179 & -3.1 \\
\hline 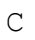 & -0.744591 & 1.109614 & -3.12154 \\
\hline & -3.08708 & 0.499928 & -4.49120 \\
\hline & _ & -0.297784 & -2.63893 \\
\hline
\end{tabular}

$$
\begin{array}{lr}
\text { C } & -0.852577 \\
\text { H } & 0.176570 \\
\text { C } & -2.027866 \\
\text { H } & -3.997497 \\
\text { H } & -0.016888 \\
\text { H } & -2.112507 \\
\text { Co } & 0.250933
\end{array}
$$

1.410185

1.355179

1.112439

0.242403

1.878104

1. 342738

0.032985
3 doublet

\begin{tabular}{|c|c|c|c|}
\hline 0 & 0.743342 & -1.710289 & 0.067186 \\
\hline O & 0.975822 & 1.557434 & 0.365747 \\
\hline $\mathrm{C}$ & 1.371932 & -2.839385 & -0.524762 \\
\hline$C$ & 0.322989 & -3.647125 & -1.345019 \\
\hline C & 2.560342 & -2.291444 & -1.490930 \\
\hline $\mathrm{C}$ & 1.794090 & -3.739155 & 0.763830 \\
\hline $\mathrm{C}$ & 0.657860 & -4.730987 & -2.172864 \\
\hline $\mathrm{C}$ & -1.034816 & -3.330511 & -1.253006 \\
\hline$C$ & 3.688835 & -3.291419 & -1.831370 \\
\hline $\mathrm{C}$ & 1.942478 & -1.812826 & -2.825731 \\
\hline $\mathrm{C}$ & 3.274848 & -1.062693 & -0.884111 \\
\hline $\mathrm{C}$ & 0.554931 & -3.898999 & 1.676184 \\
\hline $\mathrm{C}$ & 2.269879 & -5.171455 & 0.433779 \\
\hline $\mathrm{C}$ & 2.883456 & -3.065185 & 1.621594 \\
\hline $\mathrm{C}$ & -0.309504 & -5.445704 & -2.874796 \\
\hline $\mathrm{H}$ & 1.685077 & -5.043298 & -2.282543 \\
\hline $\mathrm{C}$ & -2.011390 & -4.043909 & -1.947202 \\
\hline $\mathrm{H}$ & -1.335994 & -2.512369 & -0.621790 \\
\hline $\mathrm{H}$ & 3.347085 & -4.207158 & -2.309746 \\
\hline $\mathrm{H}$ & 4.371246 & -2.811605 & -2.539889 \\
\hline $\mathrm{H}$ & 4.283479 & -3.564718 & -0.959026 \\
\hline $\mathrm{H}$ & 2.688821 & -1.252474 & -3.397141 \\
\hline $\mathrm{H}$ & 1.598315 & -2.635833 & -3.451890 \\
\hline $\mathrm{H}$ & 1.090889 & -1.150968 & -2.662256 \\
\hline $\mathrm{H}$ & 3.738752 & -1.261128 & 0.078309 \\
\hline $\mathrm{H}$ & 4.067118 & -0.741811 & -1.566893 \\
\hline $\mathrm{H}$ & 2.610813 & -0.210890 & -0.757960 \\
\hline $\mathrm{H}$ & 0.804716 & -4.562134 & 2.509954 \\
\hline $\mathrm{H}$ & 0.239899 & -2.943271 & 2.093285 \\
\hline $\mathrm{H}$ & -0.291707 & -4.341531 & 1.148859 \\
\hline $\mathrm{H}$ & 3.128808 & -5.208903 & -0.233916 \\
\hline $\mathrm{H}$ & 2.572890 & -5.657103 & 1.366691 \\
\hline $\mathrm{H}$ & 1.475552 & -5.780518 & 0.002084 \\
\hline $\mathrm{H}$ & 2.625857 & -2.035680 & 1.869030 \\
\hline $\mathrm{H}$ & 2.983512 & -3.611357 & 2.564771 \\
\hline $\mathrm{H}$ & 3.866595 & -3.075412 & 1.148137 \\
\hline $\mathrm{C}$ & -1.655905 & -5.107896 & -2.767567 \\
\hline $\mathrm{H}$ & -0.003188 & -6.274913 & -3.505511 \\
\hline $\mathrm{H}$ & -3.054681 & -3.763687 & -1.835158 \\
\hline $\mathrm{H}$ & -2.410993 & -5.667166 & -3.311006 \\
\hline C & 1.222855 & 2.722360 & 1.133972 \\
\hline $\mathrm{C}$ & 0.009956 & 3.051081 & 2.054590 \\
\hline C & 2.478388 & 2.337938 & 2.090328 \\
\hline $\mathrm{C}$ & 1.441009 & 3.891692 & 0.021307 \\
\hline $\mathrm{C}$ & -0.103030 & 4.253966 & 2.771814 \\
\hline $\mathrm{C}$ & -1.021335 & 2.126874 & 2.233077 \\
\hline C & 2.799033 & 3.369438 & 3.194763 \\
\hline $\mathrm{C}$ & 2.145006 & 1.017113 & 2.820044 \\
\hline $\mathrm{C}$ & 3.772458 & 2.101699 & 1.287474 \\
\hline $\mathrm{C}$ & 0.051433 & 4.260897 & -0.550363 \\
\hline $\mathrm{C}$ & 2.115682 & 5.202172 & 0.485782 \\
\hline
\end{tabular}
6-311G (d) 


\begin{tabular}{|c|c|c|c|}
\hline $\mathrm{C}$ & 2.306065 & 3.398480 & -1.167973 \\
\hline & -1.194209 & 4.520486 & \\
\hline & 0.667621 & 05816 & $8480-r=10$ \\
\hline & -2.117436 & 381 & \\
\hline & -0.976348 & 180498 & \\
\hline & 2.010988 & 3.432518 & \\
\hline & 3.708723 & & \\
\hline & 2.9 & & \\
\hline & 2.9 & 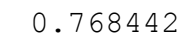 & \\
\hline & 1.22758 & 1 & \\
\hline & 2.038 & 0 . & \\
\hline & 4.22 & & \\
\hline & 4.5 & 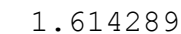 & \\
\hline & 3.6 & & \\
\hline & 0.1 & & -1 \\
\hline & -0.4 & & \\
\hline & -0 & & \\
\hline & 3.1 & & \\
\hline & 2.1 & 5. & -0 . \\
\hline & 1.5 & 5. & \\
\hline & 2.0 & & -1 \\
\hline & 2.1 & & -2 \\
\hline & 3.3 & & -0 \\
\hline & -2.2 & & \\
\hline & $-1 \cdot 2$ & & \\
\hline & -2.8 & 1. & 3. \\
\hline & -3.0 & 3 . & \\
\hline & $-1 \cdot 3$ & & -0 \\
\hline & -2.5 & -0 . & -0 \\
\hline & -2.5 & -0 & \\
\hline & -3.74 & 0 & -0.3 \\
\hline & -3.66 & -1.11 & 1.839 \\
\hline & -1.6 & -1.4 & 1. \\
\hline & -4.8 & & \\
\hline & -3 & & -1 \\
\hline & -4 & -0 . & 1 . \\
\hline & -3 & -1 & 2.69 \\
\hline & -5.7 & 0.964 & 0.190 \\
\hline & -5.7 & -0.573 & 2. \\
\hline & $-1 \cdot 4$ & 0 . & -2 . \\
\hline & -2.4 & -0 . & -3 \\
\hline & -0.4 & & -2 . \\
\hline & -2.46 & 0.0733 & -4.4828 \\
\hline & -3.1560 & -0.8311 & -2.6673 \\
\hline & -0.5221 & 1.48 & -4.302 \\
\hline & 0.3 & & -2.343 \\
\hline 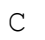 & -1.522 & & -5.0831 \\
\hline $\mathrm{H}$ & -3.2416 & -0.394888 & -5.0850 \\
\hline $\mathrm{H}$ & 0.219673 & 2.129324 & -4.75776 \\
\hline$\Pi$ & -1.5604 & 1.092652 & -6.15098 \\
\hline 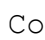 & 0.2784 & -0.007671 & -0.067 \\
\hline
\end{tabular}

3Rh doublet SDD / 6-31G (d)

$\begin{array}{rrrr}- & \\ \text { O } & 1.660734 & -0.994847 & -0.649957 \\ \text { O } & -1.847942 & -0.729003 & 0.506722 \\ \text { C } & 2.968380 & -1.383857 & -0.256141 \\ \text { C } & 3.871698 & -0.119274 & -0.162242 \\ \text { C } & 2.841287 & -2.141027 & 1.179439 \\ \text { C } & 3.486741 & -2.264880 & -1.525443 \\ \text { C } & 5.140126 & -0.107746 & 0.444849\end{array}$

\begin{tabular}{|c|c|c|c|}
\hline & 3.452010 & 1.078196 & -0.758926 \\
\hline & 3.977839 & -3.131368 & 728 \\
\hline & 2.768288 & -1.091008 & 2 \\
\hline & 1.530542 & -2.964389 & 1.28 \\
\hline & 3.280456 & -1.440285 & \\
\hline & 4.988243 & -2.632764 & -1.488 \\
\hline & 2.674803 & -3.565318 & -1.7 \\
\hline & 5.932402 & 1.041482 & 0.4 \\
\hline & 5.535134 & -1.002343 & 0. \\
\hline & 4.240219 & 2.231847 & -0.740 \\
\hline & 2.495609 & 1.101159 & -1.25 \\
\hline & 4.978335 & -2.696367 & \\
\hline & 3.819659 & -3.477497 & 2.5 \\
\hline & 5659 & -4.019368 & \\
\hline & 2.4 & -1.584040 & 3.2 \\
\hline & 570 & -0.61 & 2.5 \\
\hline & 2692 & -0.303854 & 2.0 \\
\hline & 3860 & -3.665590 & \\
\hline & 4527 & -3.544034 & 2.2 \\
\hline & 3557 & -2.326717 & 1.3 \\
\hline & 3.6 & -2.0 & -3 \\
\hline & 2.2 & -1.15 & -2. \\
\hline & 3.8 & -0.50 & -2.8 \\
\hline & 5.2 & -3.268653 & -0.6 \\
\hline & 3577 & -3.191192 & -2.40 \\
\hline & 7710 & -1.746263 & -1.4 \\
\hline & 1.6 & -3.36 & -1.7 \\
\hline & 2.9 & -4 & -2.6 \\
\hline & 2.8 & -4 & -0. \\
\hline & 7181 & 4029 & -0.11 \\
\hline & 6.9 & 1.004753 & 0.95 \\
\hline & 3.8 & 3.134230 & -1.225 \\
\hline & 6.1 & 3.1 & -0.1 \\
\hline & -3.1 & $-1 \cdot 1$ & 0 . \\
\hline & -4 & 0 . & -0.1 \\
\hline & -2 & -2.026662 & -1.29 \\
\hline & -3.647158 & -1.982377 & 1.415 \\
\hline & -5.414138 & -0.062915 & -0.487 \\
\hline & -3.516441 & 1.340666 & -0.107 \\
\hline & -4.2 & -2.522118 & $-1 \cdot 9$ \\
\hline & -2.2 & $-1 \cdot 1$ & -2.3 \\
\hline & -2. & -3 & -1.1 \\
\hline & -4.0965 & -0.942117 & 2.471 \\
\hline & -4.821915 & -2.963351 & 1.208 \\
\hline & -2.509353 & -2.797726 & 2.081 \\
\hline & -6.2 & 1.065340 & -0.709 \\
\hline & -5.8 & -1 & -0.5 \\
\hline c & -4 & 312 & -0.336 \\
\hline F & -2.471430 & 1.464195 & 0.135 \\
\hline & -4.847592 & -1.698411 & -2.3696 \\
\hline & -3.985808 & -3.168945 & -2.8010 \\
\hline & -4.900740 & -3.110136 & -1.301 \\
\hline & -2.2 & -1 & -3.318 \\
\hline H & -2.8401 & -0.180436 & -2.491 \\
\hline H & -1.2543 & -0.863275 & -2.103 \\
\hline & -2.541738 & -4.068665 & -0.5641 \\
\hline & -1.765767 & -3.656622 & -2.0913 \\
\hline & -1.114560 & -3.017877 & -0.5780 \\
\hline & -4.265551 & -1.448191 & 3.4299 \\
\hline $\mathrm{H}$ & -3.328960 & -0.178139 & 2.6266 \\
\hline & -5.024838 & -0.435671 & 2.19442 \\
\hline & -4.541491 & -3.833219 & 0.60734 \\
\hline & -5.130924 & -3.343321 & 2.19034 \\
\hline
\end{tabular}




$\begin{array}{lrrr}\mathrm{H} & -5.704692 & -2.500739 & 0.761197 \\ \mathrm{H} & -1.685245 & -2.154960 & 2.393577 \\ \mathrm{H} & -2.911740 & -3.290958 & 2.975064 \\ \mathrm{H} & -2.104332 & -3.579208 & 1.436831 \\ \mathrm{C} & -5.654610 & 2.344704 & -0.640732 \\ \mathrm{H} & -7.261536 & 0.936573 & -0.937630 \\ \mathrm{H} & -3.843848 & 3.458164 & -0.275119 \\ \mathrm{H} & -6.270381 & 3.222665 & -0.817648 \\ \mathrm{C} & 0.122843 & 1.574635 & 0.157232 \\ \mathrm{C} & 0.038225 & 2.488723 & -0.985480 \\ \mathrm{C} & 0.223186 & 2.030709 & -2.311378 \\ \mathrm{C} & -0.287222 & 3.853036 & -0.799253 \\ \mathrm{C} & 0.106105 & 2.896437 & -3.392608 \\ \mathrm{H} & 0.471881 & 0.987989 & -2.483228 \\ \mathrm{C} & -0.416415 & 4.713465 & -1.886860 \\ \mathrm{H} & -0.453852 & 4.228371 & 0.204449\end{array}$

$\begin{array}{rrrr}\mathrm{C} & -0.216947 & 4.241945 & -3.186128 \\ \mathrm{H} & 0.263295 & 2.521716 & -4.400092 \\ \mathrm{H} & -0.675999 & 5.755133 & -1.718707 \\ \mathrm{H} & -0.316355 & 4.915153 & -4.033077 \\ \mathrm{C} & 0.322698 & 2.079084 & 1.527952 \\ \mathrm{C} & 1.335680 & 3.020939 & 1.813362 \\ \mathrm{C} & -0.465438 & 1.593360 & 2.593586 \\ \mathrm{C} & 1.552051 & 3.453394 & 3.119172 \\ \mathrm{H} & 1.970030 & 3.381645 & 1.010406 \\ \mathrm{C} & -0.256778 & 2.048616 & 3.893919 \\ \mathrm{H} & -1.247025 & 0.869891 & 2.384392 \\ \mathrm{C} & 0.753667 & 2.975206 & 4.162384 \\ \mathrm{H} & 2.347399 & 4.164987 & 3.323665 \\ \mathrm{H} & -0.883089 & 1.675391 & 4.699542 \\ \mathrm{H} & 0.921548 & 3.320249 & 5.178963 \\ \mathrm{Rh} & -0.025642 & -0.268469 & -0.022548\end{array}$

Table S7. Harmonic frequencies (in $\mathrm{cm}^{-1}$ ) for species optimized at B3LYP/6-31G(d).

$\begin{array}{rrr}\text { 3 doublet } & & \\ ------- & & \\ 4.7689 & 15.3804 & 18.7270 \\ 48.91633 & 38.9320 & 46.8542 \\ 63.3676 & 51.6316 & 59.1988 \\ 77.3096 & 85.1481 & 87.4409 \\ 91.6398 & 97.4878 & 105.3095 \\ 107.9085 & 123.2000 & 128.2062 \\ 134.2458 & 151.1907 & 177.5537 \\ 189.2941 & 195.2986 & 207.6270 \\ 218.8199 & 224.2945 & 226.4460 \\ 229.0035 & 240.3812 & 247.3952 \\ 248.7381 & 254.7035 & 258.6547 \\ 264.0138 & 272.0979 & 279.6326 \\ 282.8698 & 284.8686 & 287.1265 \\ 292.8906 & 297.9835 & 303.5540 \\ 306.7266 & 312.3637 & 323.1610 \\ 325.6742 & 328.5259 & 330.0267 \\ 334.0985 & 337.3161 & 341.9226 \\ 343.8638 & 359.6197 & 366.2563 \\ 380.2994 & 386.4262 & 392.9149 \\ 405.2539 & 412.4555 & 419.3407 \\ 422.1149 & 425.5013 & 427.1353 \\ 429.1676 & 432.6660 & 437.2603 \\ 440.7311 & 442.3480 & 451.9489 \\ 454.6407 & 462.0982 & 497.8109 \\ 510.6425 & 511.7293 & 562.0678 \\ 563.5680 & 569.5161 & 570.8791 \\ 589.0360 & 595.4934 & 629.3037 \\ 632.0170 & 637.8064 & 638.4266 \\ 661.7229 & 666.6288 & 677.0457 \\ 702.6117 & 708.4510 & 716.3592 \\ 724.1194 & 739.9832 & 755.4188 \\ 760.8761 & 769.8686 & 779.0115 \\ 783.1206 & 811.1781 & 812.1334 \\ 828.4704 & 832.1061 & 852.4518 \\ 856.4495 & 863.9275 & 870.7807 \\ 876.8948 & 895.0867 & 898.1441 \\ 900.4768 & 908.1363 & 911.4613 \\ 933.9491 & 934.8589 & 938.0360\end{array}$

$\begin{array}{rrr}938.3042 & 940.2646 & 941.8314 \\ 942.4311 & 943.9898 & 945.9029 \\ 951.0653 & 951.5387 & 955.7344 \\ 965.3916 & 970.4296 & 970.6262 \\ 974.7366 & 977.8094 & 979.0356 \\ 981.7490 & 984.1317 & 992.0895 \\ 997.9724 & 1001.4335 & 1007.3726 \\ 1008.9812 & 1010.6214 & 1018.6579 \\ 1021.3886 & 1024.7321 & 1032.1372 \\ 1054.4792 & 1054.9440 & 1056.4676 \\ 1057.8339 & 1058.3443 & 1060.7555 \\ 1061.2609 & 1062.0521 & 1071.4213 \\ 1072.9559 & 1076.3522 & 1079.2324 \\ 1113.3032 & 1117.1038 & 1120.8663 \\ 1123.9544 & 1172.3032 & 1175.9220 \\ 1188.1524 & 1190.6093 & 1192.0288 \\ 1193.1029 & 1193.4771 & 1214.0734 \\ 1218.7230 & 1223.1398 & 1225.3388 \\ 1228.7965 & 1229.4399 & 1231.7266 \\ 1233.1263 & 1237.2969 & 1238.0401 \\ 1239.8008 & 1240.7882 & 1251.6560 \\ 1252.6299 & 1261.7018 & 1264.1368 \\ 1309.6858 & 1323.1985 & 1334.3407 \\ 1337.8800 & 1339.1227 & 1359.6978 \\ 1363.7109 & 1367.1186 & 1370.5274 \\ 1419.9068 & 1420.3741 & 1421.3609 \\ 1425.8337 & 1427.6173 & 1429.3144 \\ 1431.5092 & 1434.2230 & 1454.2696 \\ 1454.9647 & 1464.0241 & 1466.3011 \\ 1479.5611 & 1486.2625 & 1487.0357 \\ 1487.4173 & 1509.7730 & 1512.0403 \\ 1512.4667 & 1515.2997 & 1519.5372 \\ 1521.4839 & 1523.4479 & 1524.2732 \\ 1525.1947 & 1525.7550 & 1526.1059 \\ 1526.8162 & 1528.3934 & 1531.4203 \\ 1533.8563 & 1535.7414 & 1536.7256 \\ 1537.2651 & 1540.9105 & 1543.2065 \\ 1545.5280 & 1547.3045 & 1551.8914 \\ 1553.7802 & 1555.6850 & 1557.6627 \\ 1561.1250 & 1566.9244 & 1612.1804 \\ 1614.7151 & 1637.3996 & 1637.5632 \\ 1638.1348 & 1641.5425 & 1659.0795\end{array}$




$\begin{array}{lll}1659.7788 & 3049.9984 & 3052.2375 \\ 3052.3467 & 3052.6336 & 3053.4625 \\ 3055.3974 & 3055.9753 & 3056.2565 \\ 3062.6152 & 3063.9263 & 3067.8753 \\ 3069.4603 & 3109.4875 & 3111.4610 \\ 3117.6731 & 3117.9164 & 3119.2446 \\ 3120.6783 & 3121.2690 & 3124.4042 \\ 3126.8185 & 3128.6192 & 3140.6267 \\ 3147.2523 & 3148.7155 & 3151.1000 \\ 3152.3494 & 3153.3071 & 3154.1487 \\ 3159.7124 & 3161.0729 & 3164.8215 \\ 3165.6416 & 3167.9466 & 3176.2648 \\ 3179.5464 & 3185.4455 & 3186.3420 \\ 3186.7443 & 3187.7002 & 3191.8834 \\ 3193.7693 & 3194.7877 & 3196.3700 \\ 3202.9112 & 3206.5370 & 3207.4000 \\ 3210.0982 & 3213.7399 & 3221.0113 \\ 3224.0849 & 3244.1910 & 3258.6545 \\ 3266.4405 & 3272.7323 & 3302.8087\end{array}$

3 quartet

$\begin{array}{rrr}-38.6357 & -8.0836 & 10.2740 \\ 11.2908 & 24.3205 & 29.6925 \\ 32.9102 & 38.1840 & 47.2501 \\ 52.0090 & 54.9110 & 62.6263 \\ 65.8507 & 71.4231 & 77.9537 \\ 83.9308 & 89.2985 & 90.0983 \\ 97.8653 & 114.3767 & 116.0921 \\ 119.1508 & 139.0401 & 162.4916 \\ 166.4899 & 188.2179 & 195.1767 \\ 200.6523 & 212.6885 & 214.7629 \\ 227.7524 & 234.6754 & 245.6105 \\ 249.7637 & 254.1163 & 260.5439 \\ 264.3351 & 269.5837 & 272.6352 \\ 278.5774 & 285.1288 & 285.5691 \\ 289.0994 & 294.6109 & 301.7737 \\ 305.7058 & 309.1569 & 309.3606 \\ 322.7025 & 325.8263 & 326.8534 \\ 332.1135 & 334.2052 & 341.2941 \\ 345.6971 & 352.3953 & 357.6006 \\ 359.6121 & 361.9032 & 381.7054 \\ 399.5751 & 403.0231 & 410.0881 \\ 413.8823 & 424.2165 & 426.4356 \\ 428.1688 & 429.9331 & 432.9008 \\ 434.1120 & 437.9436 & 439.7977 \\ 444.2549 & 445.0557 & 479.5123 \\ 507.7753 & 511.8423 & 561.5476 \\ 562.4262 & 565.2775 & 566.2845 \\ 582.4887 & 593.3534 & 626.8797 \\ 629.3414 & 637.7641 & 637.9770 \\ 659.1798 & 662.7233 & 666.1491 \\ 701.2723 & 706.1548 & 721.0357 \\ 722.5590 & 743.4489 & 754.4751 \\ 758.1545 & 767.1408 & 774.9447 \\ 791.0416 & 810.6098 & 810.8481 \\ 827.4324 & 828.6383 & 856.4907 \\ 860.4135 & 867.3634 & 869.3605 \\ 881.7985 & 892.1332 & 896.0022 \\ 898.9581 & 906.2467 & 911.5543 \\ 936.0142 & 936.5628 & 937.0087 \\ 937.5971 & 940.6163 & 941.2056\end{array}$

\begin{tabular}{|c|c|c|}
\hline 948.4886 & 948.7170 & 949.9952 \\
\hline 954.7898 & 955.7095 & 958.4961 \\
\hline 965.6661 & 966.2316 & 973.8075 \\
\hline 975.5478 & 977.2299 & 980.5426 \\
\hline 982.4308 & 986.4697 & 994.3305 \\
\hline 1008.8872 & 1009.3265 & 1010.2662 \\
\hline 011.7458 & 1013.4033 & 1020.1327 \\
\hline 1020.8003 & 1049.8084 & 1052.4659 \\
\hline 1054.1631 & 1054.8897 & 1055.3882 \\
\hline 1057.2327 & 1058.9190 & 1059.3520 \\
\hline 1060.8385 & 1062.2017 & 1070.1955 \\
\hline 1071.1817 & 1091.0798 & 1100.1310 \\
\hline 1115.5610 & 1118.6186 & 1122.6240 \\
\hline 1125.3993 & 1167.8995 & 1172.0264 \\
\hline 1188.2960 & 1190.7469 & 1195.2069 \\
\hline 1196.0088 & 1207.2074 & 1213.3288 \\
\hline 1216.2460 & 1219.3710 & 1229.0302 \\
\hline 1230.1769 & 1230.4339 & 1231.8200 \\
\hline 1233.2959 & 1237.9145 & 1239.1849 \\
\hline 1241.6607 & 1242.7386 & 1251.6934 \\
\hline 1252.2224 & 1261.7898 & 1262.9501 \\
\hline 1322.1726 & 1332.9128 & 1336.9224 \\
\hline 1338.4161 & 1342.8229 & 1358.9142 \\
\hline 1360.7887 & 1368.7148 & 1371.2471 \\
\hline 1416.2571 & 1416.4880 & 1420.1664 \\
\hline 2.2379 & 1425.2841 & 1425.7886 \\
\hline 1427.1896 & 1429.1344 & 1450.0733 \\
\hline 1452.1900 & 1458.5454 & 1461.3107 \\
\hline 1479.0481 & 1486.5438 & 1487.0483 \\
\hline 1487.5280 & 1508.4620 & 1509.3238 \\
\hline 1511.6390 & 1512.8397 & 1518.0511 \\
\hline 1518.7881 & 1521.3402 & 1522.6784 \\
\hline 1523.5914 & 1525.1110 & 1525.2658 \\
\hline 1526.5968 & 1527.3437 & 1530.1070 \\
\hline 1533.2341 & 1533.5530 & 1534.6041 \\
\hline 1535.8771 & 1538.7034 & 1540.1744 \\
\hline 1543.2276 & 1544.4002 & 1549.5837 \\
\hline .7928 & 1553.7970 & 1555.1974 \\
\hline 0.1610 & 1562.1102 & 1611.1094 \\
\hline 1614.0353 & 1635.9123 & 1636.5187 \\
\hline 1641.1765 & 1645.1892 & 1658.0625 \\
\hline 1658.3439 & 3046.5423 & 3047.7210 \\
\hline 3048.0667 & 3049.0040 & 3049.3628 \\
\hline 3050.7472 & 3050.9018 & 3052.4188 \\
\hline 3057.7229 & 3061.3627 & 3062.7558 \\
\hline 3063.6777 & 3105.5331 & 3106.8157 \\
\hline 3110.7328 & 3112.0057 & 3113.2762 \\
\hline 3113.8607 & 3116.2684 & 3118.9636 \\
\hline 3121.7048 & 3124.4164 & 3134.4277 \\
\hline 3136.3494 & 3140.1410 & 3140.6793 \\
\hline 3143.2738 & 3149.6494 & 3150.3708 \\
\hline 3153.3654 & 3153.6023 & 3158.5642 \\
\hline 3162.1837 & 3166.8333 & 3171.0364 \\
\hline 3172.4327 & 3176.6719 & 3178.4160 \\
\hline 3181.2850 & 3187.0741 & 3190.1504 \\
\hline 3191.6751 & 3196.4440 & 3200.0973 \\
\hline 3202.0923 & 3202.4041 & 3205.259 \\
\hline 3211.5461 & 3215.8457 & 3221.2875 \\
\hline 3223.0436 & 3225.9732 & 3249.2114 \\
\hline 3254.4910 & 3267.4437 & 3271.4519 \\
\hline
\end{tabular}

3 sextet
948.7170
955.7095

966.2316

1013.4033

1058.9190

1062.2017

1167.8995

1219.3710

1242.7386

1261.7898

1458.5454

1486.5438

1538.7034

1544.4002

3112.0057

3140.1410

3149.6494

3.6023

3196.4440

3215.8457

3225.9732

3271.4519 


\begin{tabular}{|c|c|c|}
\hline-2.6229 & 14.2890 & 16.9459 \\
\hline 27.1062 & 33.9283 & 36.6248 \\
\hline 40.1685 & 44.1586 & 47.1493 \\
\hline 51.5704 & 55.3008 & 57.4176 \\
\hline 64.9362 & 71.1002 & 78.3343 \\
\hline 80.2854 & 88.9283 & 94.6129 \\
\hline 96.3166 & 100.7493 & 111.9771 \\
\hline 116.0743 & 120.6303 & 140.8367 \\
\hline 173.5961 & 185.1220 & 198.0619 \\
\hline 209.8949 & 212.5987 & 215.2805 \\
\hline 225.7193 & 232.5117 & 236.4750 \\
\hline 248.2767 & 250.4475 & 254.2457 \\
\hline 261.6248 & 268.9672 & 270.8606 \\
\hline 282.7488 & 285.3903 & 288.0421 \\
\hline 292.3143 & 300.4560 & 302.3994 \\
\hline 303.8997 & 310.2320 & 315.136 \\
\hline 324.0797 & 329.1161 & 332.5104 \\
\hline 335.0781 & 337.7322 & 340.4618 \\
\hline 350.8701 & 354.7073 & 363.0140 \\
\hline 368.2612 & 370.7641 & 387.6461 \\
\hline 390.3032 & 404.6115 & 406.8894 \\
\hline 411.4785 & 413.9654 & 421.6544 \\
\hline 425.0509 & 426.0545 & 429.6520 \\
\hline 433.6274 & 441.7409 & 443.4159 \\
\hline 444.4185 & 447.3942 & 492.8514 \\
\hline 509.8946 & 510.2486 & 555.6272 \\
\hline 563.6344 & 564.0082 & 568.8776 \\
\hline 569.2051 & 583.2826 & 627.1012 \\
\hline 629.6699 & 636.6354 & 636.7478 \\
\hline 658.2524 & 661.1574 & 662.9942 \\
\hline 693.7845 & 705.2854 & 720.5479 \\
\hline 721.3171 & 757.5452 & 759.3376 \\
\hline 761.4747 & 770.7615 & 771.0556 \\
\hline 800.2762 & 811.4746 & 812.2637 \\
\hline 830.7550 & 832.1731 & 834.9272 \\
\hline 845.2777 & 850.7027 & 866.8943 \\
\hline 867.8885 & 894.3457 & 895.2458 \\
\hline 896.9975 & 903.1981 & 912.4763 \\
\hline 914.9656 & 920.4263 & 936.2445 \\
\hline 936.8697 & 937.8123 & 939.2210 \\
\hline 941.4880 & 943.7293 & 948.6045 \\
\hline 950.9715 & 956.9542 & 958.5178 \\
\hline 959.4472 & 968.1480 & 969.1482 \\
\hline 970.3756 & 976.1190 & 977.0795 \\
\hline 980.3383 & 981.2571 & 986.1920 \\
\hline 991.0373 & 999.9250 & 1000.1456 \\
\hline 1002.0409 & 1004.4002 & 1018.7866 \\
\hline 1019.1082 & 1048.0796 & 1051.556 \\
\hline 1052.8223 & 1053.6819 & 1054.4585 \\
\hline 1056.9509 & 1059.1327 & 1060.2907 \\
\hline 1061.2998 & 1062.1883 & 1071.7491 \\
\hline 1073.1864 & 1082.3615 & 1093.234 \\
\hline 1110.5800 & 1119.2878 & 1122.3180 \\
\hline 1126.1747 & 1172.4118 & 1174.1568 \\
\hline 1188.3416 & 1189.1973 & 1193.0677 \\
\hline 1193.4036 & 1193.5068 & 1205.0792 \\
\hline 1223.5810 & 1224.9099 & 1225.2980 \\
\hline 1229.9216 & 1231.7468 & 1232.2070 \\
\hline 1234.3733 & 1237.9670 & 1239.969 \\
\hline 1240.4513 & 1242.1591 & 1253.809 \\
\hline 1253.9963 & 1263.0255 & 1264.856 \\
\hline 1306.7005 & 1321.2278 & 1326.201 \\
\hline
\end{tabular}

$\begin{array}{lll}1337.1461 & 1337.4892 & 1363.5644 \\ 1363.7239 & 1365.5466 & 1366.3971 \\ 1419.8252 & 1420.7980 & 1422.9476 \\ 1427.0683 & 1427.8845 & 1429.8608 \\ 1430.4449 & 1432.4036 & 1453.5824 \\ 1455.8137 & 1462.0770 & 1465.1304 \\ 1475.8583 & 1483.4308 & 1487.5327 \\ 1488.0881 & 1509.6801 & 1511.0446 \\ 1511.8820 & 1512.8037 & 1514.2539 \\ 1516.3649 & 1519.1050 & 1520.0202 \\ 1520.1175 & 1520.9349 & 1522.1631 \\ 1523.7008 & 1528.2003 & 1528.7579 \\ 1533.3856 & 1535.2468 & 1536.2579 \\ 1537.4730 & 1539.4231 & 1540.2543 \\ 1545.1961 & 1545.4670 & 1550.2313 \\ 1551.6831 & 1553.9318 & 1555.4330 \\ 1558.8843 & 1562.4199 & 1597.8360 \\ 1603.2095 & 1623.4680 & 1632.5984 \\ 1637.3940 & 1637.6481 & 1658.4063 \\ 1658.9430 & 3052.4814 & 3052.9555 \\ 3053.6621 & 3054.1023 & 3055.9425 \\ 3056.4337 & 3057.9869 & 3058.3569 \\ 3064.4010 & 3065.2882 & 3070.1729 \\ 3072.5776 & 3110.2786 & 3111.9176 \\ 3113.4123 & 3116.9067 & 3118.9472 \\ 3120.5266 & 3121.8710 & 3123.0892 \\ 3129.0699 & 3129.4177 & 3132.1316 \\ 3139.7837 & 3142.5253 & 3146.9616 \\ 3147.9584 & 3149.7869 & 3153.6040 \\ 3157.6916 & 3158.5996 & 3160.6593 \\ 3166.7054 & 3166.9741 & 3169.7832 \\ 3175.2334 & 3178.2813 & 3179.7745 \\ 3180.1904 & 3181.8206 & 3182.5487 \\ 3183.5716 & 3190.1459 & 3192.5287 \\ 3193.7889 & 3194.8218 & 3205.2798 \\ 3207.0355 & 3207.1002 & 3208.5999 \\ 3213.9170 & 3219.3697 & 3256.3336 \\ 3256.5830 & 3265.2566 & 3283.0663 \\ & & \end{array}$

3Rh doublet SDD / 6-31G (d)

$\begin{array}{rr}16.2214 & 23.0651 \\ 33.0494 & 38.0801 \\ 48.6308 & 56.7001 \\ 60.0425 & 72.6515 \\ 79.1021 & 82.0211 \\ 90.2602 & 95.3441 \\ 114.2660 & 124.3403 \\ 136.6814 & 162.4601 \\ 184.8745 & 197.6203 \\ 211.3609 & 218.6615 \\ 232.7228 & 236.9044 \\ 250.4867 & 253.3951 \\ 268.8905 & 272.2170 \\ 282.2583 & 285.2104 \\ 296.9990 & 304.5136 \\ 308.2546 & 314.8252 \\ 325.8433 & 329.0158 \\ 333.5463 & 335.8269 \\ 347.1801 & 365.8420 \\ 378.6447 & 396.7869\end{array}$




\begin{tabular}{|c|c|c|c|c|c|}
\hline 397.0805 & 410.2393 & 414.1045 & 1251.5807 & 1262.1782 & 1263.7948 \\
\hline 419.6962 & 423.8202 & 427.6865 & 1306.8750 & 1327.6774 & 1335.4310 \\
\hline 430.8754 & 433.5889 & 435.7260 & 1337.7005 & 1342.0809 & 1359.9110 \\
\hline 437.4411 & 441.6098 & 446.3508 & 1361.7849 & 1370.8997 & 1372.4757 \\
\hline 449.7104 & 465.5873 & 496.3239 & 1416.9622 & 1420.7753 & 1422.7139 \\
\hline 510.2678 & 518.4483 & 561.9905 & 1424.3049 & 1426.7034 & 1427.2803 \\
\hline 564.3124 & 566.3389 & 568.8405 & 1428.8017 & 1433.3012 & 1451.7209 \\
\hline 588.9049 & 607.2476 & 629.6171 & 1453.2768 & 1459.7137 & 1464.5221 \\
\hline 633.7286 & 636.6022 & 637.0839 & 1482.2859 & 1486.2566 & 1487.2057 \\
\hline 654.1768 & 660.2796 & 689.7222 & 1489.5733 & 1507.9968 & 1509.8318 \\
\hline 701.4780 & 706.2591 & 708.7879 & 1510.3293 & 1514.1442 & 1516.7994 \\
\hline 717.9879 & 720.9035 & 722.4026 & 1518.3317 & 1518.9877 & 1520.1840 \\
\hline 755.8679 & 760.4686 & 770.2372 & 1522.8604 & 1526.3565 & 1526.9407 \\
\hline 783.0546 & 811.4619 & 812.2007 & 1528.1378 & 1530.3000 & 1531.4535 \\
\hline 827.7441 & 828.2334 & 855.4721 & 1532.7750 & 1535.3441 & 1535.8310 \\
\hline 860.9705 & 863.7539 & 865.1241 & 1537.9529 & 1538.3090 & 1538.6950 \\
\hline 892.1776 & 895.1285 & 896.1478 & 1543.4027 & 1544.7059 & 1549.6688 \\
\hline 905.7218 & 911.0582 & 932.7279 & 1551.6914 & 1555.0723 & 1555.4141 \\
\hline 933.3239 & 935.4596 & 937.2174 & 1559.2903 & 1560.7986 & 1619.1799 \\
\hline 938.6518 & 942.0269 & 942.1850 & 1621.5418 & 1636.1550 & 1636.4643 \\
\hline 943.7718 & 948.4796 & 948.7672 & 1646.1171 & 1648.5488 & 1657.3253 \\
\hline 951.3437 & 953.4659 & 963.9775 & 1658.5931 & 3043.3513 & 3048.6734 \\
\hline 967.4823 & 971.3612 & 973.1816 & 3050.0174 & 3050.1814 & 3050.3552 \\
\hline 974.9838 & 977.6753 & 978.9800 & 3051.8213 & 3052.8076 & 3054.2755 \\
\hline 981.6340 & 983.1604 & 993.8144 & 3058.9563 & 3061.7755 & 3062.6173 \\
\hline 995.1559 & 1002.4258 & 1003.7360 & 3064.2178 & 3098.1168 & 3106.4741 \\
\hline 1004.8667 & 1009.8507 & 1011.7510 & 3106.8942 & 3109.9740 & 3110.3287 \\
\hline 1014.2661 & 1020.0161 & 1021.4183 & 3117.2403 & 3117.6524 & 3119.5667 \\
\hline 1053.7107 & 1054.3784 & 1057.7323 & 3121.3237 & 3124.5480 & 3127.2659 \\
\hline 1058.3588 & 1058.4995 & 1059.3674 & 3134.0187 & 3138.0485 & 3139.7549 \\
\hline 1059.7692 & 1061.7941 & 1071.2947 & 3144.1513 & 3145.1129 & 3147.7684 \\
\hline 1072.0233 & 1075.7427 & 1077.4090 & 3149.4567 & 3151.0592 & 3156.9362 \\
\hline 1113.0275 & 1116.1076 & 1118.9041 & 3169.3315 & 3176.0871 & 3176.1877 \\
\hline 1123.6698 & 1174.7107 & 1176.0687 & 3177.4428 & 3178.1561 & 3185.2357 \\
\hline 1188.7142 & 1190.5181 & 1194.1110 & 3186.2615 & 3186.5492 & 3188.8053 \\
\hline 1194.9990 & 1201.0611 & 1216.0061 & 3190.3115 & 3198.4138 & 3198.7699 \\
\hline 1217.5035 & 1219.7692 & 1225.1941 & 3203.8615 & 3204.3420 & 3209.2789 \\
\hline 1227.5861 & 1228.6147 & 1229.5253 & 3210.4840 & 3217.6361 & 3220.507 \\
\hline 1230.0065 & 1236.3047 & 1237.3008 & 3223.9000 & 3226.9025 & 3253.601 \\
\hline 1239.1540 & 1239.7683 & 1250.5012 & 3255.4091 & 3277.2582 & 3287.721 \\
\hline
\end{tabular}

Table S8. Energies (in $\mathrm{E}_{\mathrm{h}}$ ) for all species at the B3LYP/6-31G(d) level of theory (SDD for Rh). Some small $\left(<50 \mathrm{~cm}^{-1}\right)$ imaginary frequencies corresponding to methyl and/or phenyl rotations in the alkoxide ligand were ignored for the higher energy spin states of $\mathbf{3}$.

\begin{tabular}{|c|c|c|c|}
\hline Species & E(SCF) & H(gas) & G(gas) \\
\hline 3 doublet & -3205.335533 & -3204.398353 & -3204.528927 \\
\hline 3 quartet & -3205.324277 & -3204.390002 & -3204.519235 \\
\hline 3 sextet & -3205.315018 & -3204.380249 & -3204.511710 \\
\hline quartet @ 3 doublet & -3205.312649 & - & - \\
\hline $\mathbf{3}_{\text {Rh }}$ doublet & -1933.220962 & -1932.284802 & -1932.416418 \\
\hline
\end{tabular}




\section{References}

1. Bellow, J. A.; Martin, P. D.; Lord, R. L.; Groysman, S. Inorg. Chem. 2013, 52, 12335-12337.

2. Bellow, J. A.; Yousif, M.; Fang, D.; Kratz, E. G.; Cisneros, G. A.; Groysman, S. Inorg. Chem. 2015, 54, 5624-5633.

3. Hu, M.; Rong, J.; Miao, W.; Ni, C.; Han, Y.; Hu, J. Org. Lett. 2014, 16, 2030-2033.

4. Höfer, P.; Grupp, A.; Nebenführ, H.; Mehring, M. Chem. Phys. Lett., 1986, 132, 279-282.

5. Gemperle, C.; Aebli, A.; Schweiger, A.; Ernst, R. R. J. Magn. Res. 1990, 88, 241-256.

6. This program can be downloaded from http://www.chem.cmu.edu/groups/hendrich/facilities/ and the spectral-simulation part of the software can be activated upon request.

7. (a) Stoll, S.; Schweiger, A. J. Magn. Reson. 2006, 178, 42. (b) Stoll, S.; Britt, R.D. Phys. Chem. Chem. Phys. 2009, 11, 6614.

8. Liu, H.; Wei, Y.; Cai, C. New J. Chem. A 2016, 40, 674-678.

9. Evans, D. F. J. Chem. Soc., 1959, 2003-2005.

10. Dogutan, D. K.; Stoian, S. A.; McGuire Jr, R.; Schwalbe, M.; Teets, T. S.; Nocera, D. G; J. Am. Chem. Soc. 2011, 133, 131-140.

11. Ozarowski, A.; Lee, H. M.; Balch, A. L. J. Am. Chem. Soc. 2003, 125, 12606-12614.

12. Parr, R.G.; Yang, W. Density-functional theory of atoms and molecules; Oxford University Press: New York, 1989.

13. Gaussian 09, Revision D.01, M. J. Frisch, G. W. Trucks, H. B. Schlegel, G. E. Scuseria, M. A. Robb, J. R. Cheeseman, G. Scalmani, V. Barone, B. Mennucci, G. A. Petersson, H. Nakatsuji, M. Caricato, X. Li, H. P. Hratchian, A. F. Izmaylov, J. Bloino, G. Zheng, J. L. Sonnenberg, M. Hada, M. Ehara, K. Toyota, R. Fukuda, J. Hasegawa, M. Ishida, T. Nakajima, Y. Honda, O. Kitao, H. Nakai, T. Vreven, J. A. Montgomery, Jr., J. E. Peralta, F. Ogliaro, M. Bearpark, J. J. Heyd, E. Brothers, K. N. Kudin, V. N. Staroverov, R. Kobayashi, J. Normand, K. Raghavachari, A. Rendell, J. C. Burant, S. S. Iyengar, J. Tomasi, M. Cossi, N. Rega, J. M. Millam, M. Klene, J. E. Knox, J. B. Cross, V. Bakken, C. Adamo, J. Jaramillo, R. Gomperts, R. E. Stratmann, O. Yazyev, A. J. Austin, R. Cammi, C. Pomelli, J. W. Ochterski, R. L. Martin, K. Morokuma, V. G. Zakrzewski, G. A. Voth, P. Salvador, J. J. Dannenberg, S. Dapprich, A. D. Daniels, Ö. Farkas, J. B. Foresman, J. V. Ortiz, J. Cioslowski, and D. J. Fox, Gaussian, Inc., Wallingford CT, 2009.

14. (a) Vosko, S. H.; Wilk, L.; Nusair, M. Can. J. Phys. 1980, 58, 1200. (b) Lee, C.; Yang, W.; Parr, R.G. Phys. Rev. B 1988, 37, 785. (c) Becke, A. D. J. Chem. Phys. 1993, 98, 5648. (d) Stephens, P.J.; Devlin, F. J.; Chabalowski, C. F.; Frisch, M.J. J. Phys. Chem. 1994, 98, 11623. 
15. (a) Schlegel, H. B.; McDouall, J. J. in Computational Advances in Organic Chemistry; Oeretir, C; Csizmadia, I. G., Eds.; Kluwer Academic: Amsterdam, The Netherlands, 1991. (b) Bauernschmitt, R.; Ahlrichs, R. J. Chem. Phys. 1996, 104, 9047.

16. (a) Schlegel, H. B. J. Comput. Chem. 1982, 3, 214. (b) Schlegel, H. B. WIREs Comput. Mol. Sci. 2011, 1,790 .

17. (a) Perdew, J. P.; Burke, K.; Ernzerhof, M. Phys. Rev. Lett. 1996, 77, 3875. (b) Cohen, A. J.; Handy, N. C. Mol. Phys. 2001, 99, 403.

18. Swart, M.; Groenhof, A. R.; Ehlers, A. W.; Lammertsma, K. J. Phys. Chem. A 2004, 108, 5479. 19. (a) Chai, J.-D.; Head-Gordon, M. J. Chem. Phys. 2008, 128, 084106. (b) Chai, J.-D.; Head-Gordon, M. Phys. Chem. Chem. Phys. 2008, 10, 6615.

20. (a) 6-31G(d) is not defined for Rh, so the Stuttgart basis including an ECP was employed for this atom only. (b) Bergner, A.; Dolg, M.; Küchle, W.; Stoll, H.; Preuß, H. Mol. Phys. 1993, 80, 1431. 21. (a) Neese, F. ORCA - An ab initio, Density Functional, and Semiempirical Program Package, Version 3.0.0. (b) Neese, F. WIREs Comput. Mol. Sci. 2012, 2, 73.

22. Martin, R. L. J. Chem. Phys. 2003, 118, 4775. 